\title{
FACTORES DE RIESGO PARA EL DESPLAZAMIENTO, PROTECCIÓN DE TIERRAS Y GARANTÍAS DE NO REPETICIÓN EN ZONAS VULNERABLES DE ANTIOQUIA.
}

Cuarta entrega de la investigación realizada sobre el estado actual de los derechos de las víctimas de desplazamiento forzado en el departamento de Antioquia, 2010-20115.

SOCIO-DEMOGRAPHIC PROFILE OF DISPLACED POPULATION IN ANTIOQUIA.

Recibido: diciembre de 2011 - Revisado: febrero 28 de 2012 - Aceptado: 30 de mayo de 2012

Por: Nicolás Espinosa Menéndez ${ }^{1}$, Adriana Galindo Rosero ${ }^{2}$,

Wilder Bastidas Lopera ${ }^{3}$, Juan Esteban Monsalve Rojas ${ }^{4}$.

\section{RESUMEN:}

El siguiente artículo es un informe de investigación que recoge apartes del documento sobre el estado actual del Goce Efectivo de Derechos de la población víctima del desplazamiento Forzado en Antioquia. El artículo se centra, en particular, en establecer de manera estadística tanto el comportamiento anual del desplazamiento forzado desde 1997 como de algunos indicadores del conflicto armado en territorios vulnerables del departamento (reconocidos como aquellos sobre los cuales han recaído alertas tempranas). Para tal efecto el artículo da cuenta de la metodología utilizada para dimensionar el nivel de protección que cuentan los territorios, ofrece un balance de algunas afectaciones que vulneran la seguridad de tales zonas (acciones armadas, homicidios, eventos de minas antipersona) y establece el estado y alcance actual de la protección de tierras en Antioquia.

\section{PALABRAS CLAVE:}

Desplazamiento forzado, Prevención, Protección de Tierras, Garantías de no Repetición.

\section{ABSTRACT:}

This article contains the main results of a research oriented to the carrying out of a demographic characterization of the population victim of displacement in Antioquia. In order to carry out a rigorous exercise that would pick up the conditions of life of this population, the research team designed a methodological strategy starting from the crossing of different official databases. Such a strategy enabled the characterization of reliable, up-to-date and verifiable data on more than the third part of the population.

\section{KEY WORDS AND EXPRESSIONS:}

Displacement forced, victims, profiles socio-demographic, social indicators, Antioquia.

${ }^{1}$ Sociólogo. Mg. En Antropología. Analista del Observatorio de Desplazamiento Forzado Gobernación de Antioquia, Colombia. Docente investigador Facultad de Derecho, Universidad San Buenaventura. Investigador del grupo Cultura, Violencia y Territorio de la Universidad de Antioquia. Nicolas.espinosa@usbmed.edu.co .

${ }^{2}$ Socióloga. Coordinadora procesos técnicos del Observatorio de desplazamiento Forzado, Gobernación de Antioquia, Colombia. adrianagalindo09@gmail.com Adriana.galindo@gobantioquia.gov.co.

Gerente en sistemas de información. Coordinador del Observatorio de Desplazamiento Forzado

Gobernación de Antioquia, Colombia. Investigador del grupo GIDPAD, Universidad de San Buenaventura Colombia. bastidas.wilder3@gmail.com wilder.bastidas@gobantioquia.gov.co .

${ }^{4}$ Ingeniero de Sistemas. Coordinador de procesos técnicos Observatorio de Desplazamiento Forzado Gobernación de Antioquia. Investigador del grupo Cultura, Violencia y Territorio Universidad de Antioquia. piuantioquia.observatorio@gmail.com . 


\section{Introducción.}

Tras constatar el estado de cosas inconstitucional de la atención a las personas en situación de desplazamiento realizado por la Corte Constitucional en la sentencia T-025, la Corte exigió (entre otras tantas cosas, y en sintonía con la perspectiva de los Principios enunciados) que el gobierno nacional y los gobiernos locales deben realizar un seguimiento permanente de los riesgos que desafian la prevención del desplazamiento. Este tipo de riesgos y la magnitud de su presencia en Antioquia durante el periodo 1998-2010 son materia de este artículo, la cuarta y última entrega de una serie de textos que se desprenden del Informe de Goce Efectivo de Derechos (GED) elaborado por el Observatorio del Desplazamiento Forzado de la Gobernación de Antioquia.

El marco desde el cual se concibe la naturaleza de la protección frente a los riesgos del desplazamiento lo estableció el Consejo Económico y Social de las Naciones Unidas quien definió una serie de "Principios Rectores de los Desplazamientos Internos" que demarcan los parámetros por medio de los cuáles los gobiernos deben atender las situaciones de desplazamiento forzado que se vivan en sus países. Esta serie de Principios Rectores tienen por objeto tratar:

(...)las necesidades específicas de los desplazados internos de todo el mundo, determinando los derechos y garantías necesarios para su protección. Los Principios reflejan y no contradicen la normativa internacional de derechos humanos y el derecho humanitario internacional. Reafirman las normas aplicables a los desplazados internos, que se encuentran sumamente dispersas en los instrumentos existentes, esclarecen las ambigüedades que puedan existir y tratan de colmar las lagunas identificadas en la compilación y análisis. Se aplican a las diferentes fases de los desplazamientos, ya que conceden protección contra los desplazamientos arbitrarios, proporcionan acceso a la protección y asistencia durante los desplazamientos y garantías durante el regreso o el asentamiento y la reintegración sustitutorios (Acnur 1998:S.P.).

La situación del desplazamiento en el departamento de Antioquia, como en el resto del país, demuestra una impresionante magnitud de personas que a lo largo de los 12 años estudiados (1997-2010) han sido desplazadas. Para dimensionar tal situación, la siguiente tabla da cuenta del total de personas desplazadas y el número de estas que ha sufrido mas de un desplazamiento.

Población en situación de desplazamiento

Registran más de un desplazamiento

Solo registran un desplazamiento

Total

\section{Número}

9258

620515

629773

\section{Porcentaje} $1,47 \%$ $98,53 \%$ $100 \%$

Tabla 01: Departamento de Antioquia. Relación de población con respecto al número de veces que fue desplazada. Fuente: Sipod diciembre de 2010. 
Como se puede apreciar en la siguiente tabla (NO. 02) la distribución temporal de este total de personas desplazadas presenta que los años que registran mayor número de desplazamientos corresponden a 1997, 2000, 2001 y 2002:

\begin{tabular}{|lccc} 
Año & $\begin{array}{c}\text { Personas registradas en } \\
\text { el Sipod distribuidas } \\
\text { por fecha de valoración }\end{array}$ & $\begin{array}{c}\text { Personas incluidas en el } \\
\text { Sipod distribuidas por } \\
\text { fecha de valoración }\end{array}$ & $\begin{array}{c}\text { Personas incluidas en el } \\
\text { Sipod distribuidas por año } \\
\text { de desplazamiento }\end{array}$ \\
\hline 1997 & 1000 & 985 & 122391 \\
\hline 1998 & 10046 & 9894 & 30475 \\
\hline 1999 & 2651 & 2486 & 26889 \\
\hline 2000 & 80067 & 75379 & 84241 \\
\hline 2001 & 79089 & 74374 & 78796 \\
\hline 2002 & 53269 & 46679 & 54057 \\
\hline 2003 & 31294 & 26662 & 31487 \\
\hline 2004 & 29429 & 24411 & 30410 \\
\hline 2005 & 40227 & 36403 & 34150 \\
\hline 2006 & 47170 & 40404 & 29554 \\
\hline 2007 & 73538 & 65951 & 28021 \\
\hline 2008 & 73294 & 50592 & 26560 \\
\hline 2009 & 115075 & 85516 & 20848 \\
\hline 2010 & 132833 & 85634 & 17007 \\
\hline Sin dato & 7271 & 4403 & 14887 \\
\hline Total & $\mathbf{7 7 6 . 2 5 3}$ & $\mathbf{6 2 9 . 7 7 3}$ & $\mathbf{6 2 9 . 7 7 3}$ \\
\hline
\end{tabular}

Tabla 02: Departamento de Antioquia. Distribución de población desplazada por año de desplazamiento, valoración e inclusión. Fuente: Sipod diciembre 2010, formato cubo. Procesamiento Oddif julio $2011^{7}$.

En términos operativos, y apelando al mandato internacional de los Principios Rectores de la ONU antes mencionados, en cuanto a la prevención del desplazamiento existen dos principios relativos a la protección, el principio cinco y el principio 22: el principio cinco que establece que "todas las autoridades y órganos internacionales respetarán y harán respetar las obligaciones que les impone el derecho internacional, incluidos los derechos humanos y el derecho humanitario, en toda circunstancia, a fin de prevenir y evitar la aparición de condiciones que puedan provocar el desplazamiento de personas.”, y el principio 22 que define el derecho a la protección frente a prácticas discriminatorias basadas en la condición de desplazamiento. 
Resulta de suma importancia denotar que estos Principios Rectores fueron la base interpretativa y de aplicación de la Ley 387 de 1997 que a continuación se reseñará en los apartados que tienen que ver con la prevención del desplazamiento. Los Principios Rectores de los Desplazamientos Internos han pasado a integrar el Bloque de Constitucionalidad, pues la Corte Constitucional advierte que dichos Principios tienen fuerza vinculante, pese a que no han sido aprobados mediante un tratado internacional, "dado que ellos fundamentalmente reflejan y llenan las lagunas de lo establecido en tratados internacionales de derechos humanos y que han recibido una gran aceptación por parte de distintos organismos internacionales de derechos humanos", por lo cual la corporación considera que "deben ser tenidos como parámetros para la creación normativa y la interpretación en el campo de la regulación del desplazamiento forzado y la atención a las personas desplazadas por parte del Estado. Lo anterior, claro está, sin perjuicio de que todos los preceptos que reiteran normas ya incluidas en tratados internacionales de Derechos Humanos y del Derecho Internacional Humanitario aprobados por Colombia gocen de rango constitucional, como lo señala el artículo 93 de la Constitución" ${ }^{8}$.Estos principios desde entonces han supuesto varios argumentos de sustentación en algunas de las sentencias de la Corte Constitucional ${ }^{9}$.

A partir de la Ley 387 se adoptaron medidas para la prevención del desplazamiento forzado y la atención, protección, consolidación y estabilización socioeconómica de las víctimas. En su artículo $3^{\circ}$ la ley aclara que "Es responsabilidad del Estado colombiano formular las políticas y adoptar las medidas para la prevención del desplazamiento forzado; la atención, protección y consolidación y estabilización socioeconómica de los desplazados internos por la violencia". Ahora bien, en el artículo $8^{\circ}$, denominado "De las acciones de prevención de los comités municipales", establece:

- Acciones jurídicas. Los miembros del comité municipal deberán orientar a comunidades que puedan verse afectadas por un hecho de desplazamiento, en la solución, por vías jurídicas e institucionales, de los conflictos que puedan generar tal situación. Así mismo, analizarán la viabilidad de las acciones jurídicas y recomendarán o decidirán la interposición oportuna de los recursos constitucionales o legales pertinentes que permitan minimizar o erradicar procesos embrionarios de persecución o violencia.

- Los miembros del comité municipal tratarán de prevenir los procesos embrionarios de desplazamiento proponiendo mecanismos alternativos de solución de conflictos.

- Acciones asistenciales. Los miembros del comité municipal deberán evaluar las necesidades insatisfechas de las personas o comunidades que eventualmente puedan precipitar un proceso de desplazamiento forzado. Deberán con base en dicha evaluación, tomar las medidas de asistencia del caso (Ibídem).

Así mismo, el gobierno debe contar con un Plan Nacional que contribuya a la prevención efectiva del desplazamiento forzado para que alli se diseñen y adopten "... medidas sociales, económicas, jurídicas, políticas y de seguridad, orientadas a la prevención y superación de las causas que generan el desplazamiento forzado" (Ibídem). Más adelante, en la sección 3 de la ley, el artículo 14 establece que -en torno a la prevención- "Con el objeto de prevenir el desplazamiento forzado por la violencia, el Gobierno Nacional adoptará entre otras las siguientes medidas: 
- Estimar la constitución de grupos de trabajo para la prevención y anticipación de los riesgos que puedan generar el desplazamiento.

- Promover actos ciudadanos y comunitarios de generación de la convivencia pacífica y la acción de la fuerza pública contra los factores de la perturbación.

- Desarrollar acciones para evitar la arbitrariedad, discriminación y para mitigar los riesgos contra la vida, la integridad de las personas, y los bienes patrimoniales de la población desplazada.

- Diseñar y ejecutar un plan de Difusión del Derecho Internacional Humanitario, y

- Asesorar a las autoridades departamentales y municipales encargadas de los planes de desarrollo para que se incluyan los programas de prevención y atención" (Ibídem).

Todos los elementos anteriores son recogidos por la Corte Constitucional en la sentencia T025 de 2004 cuando dictaminó el estado de cosas inconstitucional. Es decir, su cumplimiento es de carácter obligatorio para los entes nacionales, regionales y locales. Ahora bien: ¿de qué manera-entonces-y en qué medida puede establecerse el estado actual de la prevención en el contexto colombiano, en particular en el Departamento de Antioquia? A lo largo de este artículo serán expuestos los prolegómenos metodológicos que guiaron la construcción y medición de la batería de indicadores establecidos por la Corte para dar cuenta de la dimensión de la prevención del desplazamiento y será expuesto, a manera de informa de resultados, el balance de los indicadores medidos ${ }^{10}$.

Para dar cuenta de los retos a que se enfrentan las políticas de atención, el artículo está dividido en cuatro secciones. La primera compendia los parámetros metodológicos desde los cuáles se calcularon los indicadores de prevención y los criterios para la delimitación territorial del cálculo: las zonas objeto del levantamiento de Alertas Tempranas por el Comité Interinstitucional de Alertas Tempranas (CIAT). Estas regiones han sido llamadas "zonas CIAT". La segunda sección recoge los resultados de la medición de indicadores establecidos por la corte ((acciones armadas, homicidios, eventos por minas antipersona) y la expresión cartográfica de los mismos. La tercera sección da cuenta de la distribución espacial en el departamento de la protección de tierras a la que han acudido personas desplazadas o en riesgo de desplazamiento. La última parte, a manera de conclusión, ofrece un balance de las garantías de no repetición del desplazamiento en Antioquia.

\section{Metodologia.}

Delimitación espacial (regiones cubiertas por los informes de Alertas Tempranas) y parámetros metodológicos para la medición e indicadores.

Para la medición de los indicadores sectoriales asociados al derecho a la prevención del desplazamiento forzado se utilizaron las siguientes bases de datos: a) Sipod - formato cubo de Acción Social; b) el Registro Único de Predios y Territorios Abandonados - Rupta- del Incoder, c) la base de datos del proyecto de Acción integral contra minas de la Secretaría de Gobierno del departamento de Antioquia. Otras fuentes consultadas fueron los informes de riesgo emitidos por el Comité Interinstitucional de Alertas Tempranas del Ministerio del Interior y de Justicia - CIAT, la información proveniente del Observatorio de derechos humanos y derecho 
internacional humanitario de la Vicepresidencia de la República y de los comités locales de atención integral a la población desplazada. Las particularidades de las metodologías de cálculo se presentarán en las fichas técnicas y comentarios técnicos de cada uno de los indicadores.

Para poyar la comprensión de los indicadores de prevención, y puesto que la medición de estos es exigida para las zonas vulnerables del territorio, a saber: aquellas sobre las que han sido sujeto de alertas tempranas, requiere de la presentación de aspectos básicos sobre ese Sistema de Alertas Tempranas - SAT y del Comité Interinstitucional de Alertas Tempranas del Ministerio del Interior y de Justicia - CIAT. La caracterización de este programa fue realizado por la abogada Carolina Tello (2002), quien señala que:

En el año 1998, la Defensoría del Pueblo en cooperación con el Programa de las Naciones Unidas para el Desarrollo empezó a diseñar estrategias de prevención de las violaciones atroces a los derechos humanos. Esta iniciativa fue reforzada con el proyecto de asistencia técnica preparatoria $\mathrm{N}^{\circ} \mathrm{Col}$ 98/006 a 01/99, conocido como "Acciones Preventivas en Apoyo de la Defensa de los Derechos Humanos" y que sirvió para impulsar una nueva propuesta sobre la base de prevenir hechos violentos empleando un "Sistema de Alertas Tempranas". Posteriormente en el año de 1999 el Gobierno ordenó la preparación y formulación del documento Conpes 3057 "Plan Humanitario" con el cual se traza el plan de acción para la prevención y atención del desplazamiento forzado (...) de acuerdo con la Defensoría del Pueblo el SAT es un proyecto defensorial conformado por un conjunto de elementos que se articulan en un proceso de recepción, verificación, análisis, valoración, clasificación, comunicación y seguimiento de informaciones creíbles y factibles de ocurrencia de violaciones masivas de derechos humanos, acaecidas en el contexto del conflicto armado interno, que arroja diversos productos tales como informes, análisis y "Alertas Tempranas o de Inminencia", las cuales son dirigidas a las autoridades competentes para procurar su respuesta, tomando en cuenta su gradualidad (2002:6).

Posteriormente y mediante el Decreto 2780 de agosto 3 de 2010 se creó la Comisión Intersectorial de Alertas Tempranas (CIAT). En su artículo $1^{\circ}$ este decreto enuncia:

Créase la Comisión Intersectorial de Alertas Tempranas (CIAT), la cual recomendará al Ministro del Interior y de Justicia, a través de la instancia operativa, la emisión o no de alertas tempranas y la implementación de medidas dirigidas a las autoridades competentes, para la prevención de violaciones al derecho a la vida, libertad, integridad y seguridad personal e infracciones a las normas del derecho internacional humanitario, así como la realización del seguimiento de las acciones implementadas por las autoridades, teniendo como insumo los informes de riesgo y notas de seguimiento remitidos por la Defensoría del Pueblo, o la información proveniente de cualquier autoridad competente, que advierta la existencia de un eventual riesgo. Las disposiciones contenidas en el presente decreto están enmarcadas dentro del sistema de alertas tempranas (Tello 2002:7).

La medición de los indicadores de prevención, exceptuando el registro anual de personas desplazadas, se realiza considerando las estadísticas de los municipios antioqueños con informes del sistema de alertas tempranas y comprenden el periodo 2000 a 2010, de manera congruente con la fecha en que se activó el Sistema.

238

AGO.USB Medellín-Colombia V. $12 \quad N^{\circ} 2$ PP. 214- 547 Julio-Diciembre 2012 ISSN: 1657-8031 
La delimitación de la región para la medición y cálculo de indicadores de prevención comprendió a los municipios objeto de Alertas Tempranas e Informes de Riesgos Electorales, elaborados por el Comité Intersectorial de Alertas tempranas - CIAT - se destacan los límites municipales de la zona. El siguiente mapa señala los municipios declarados con algún tipo de riesgo electoral (medio, alto, extremo) y/o Alerta Temprana.

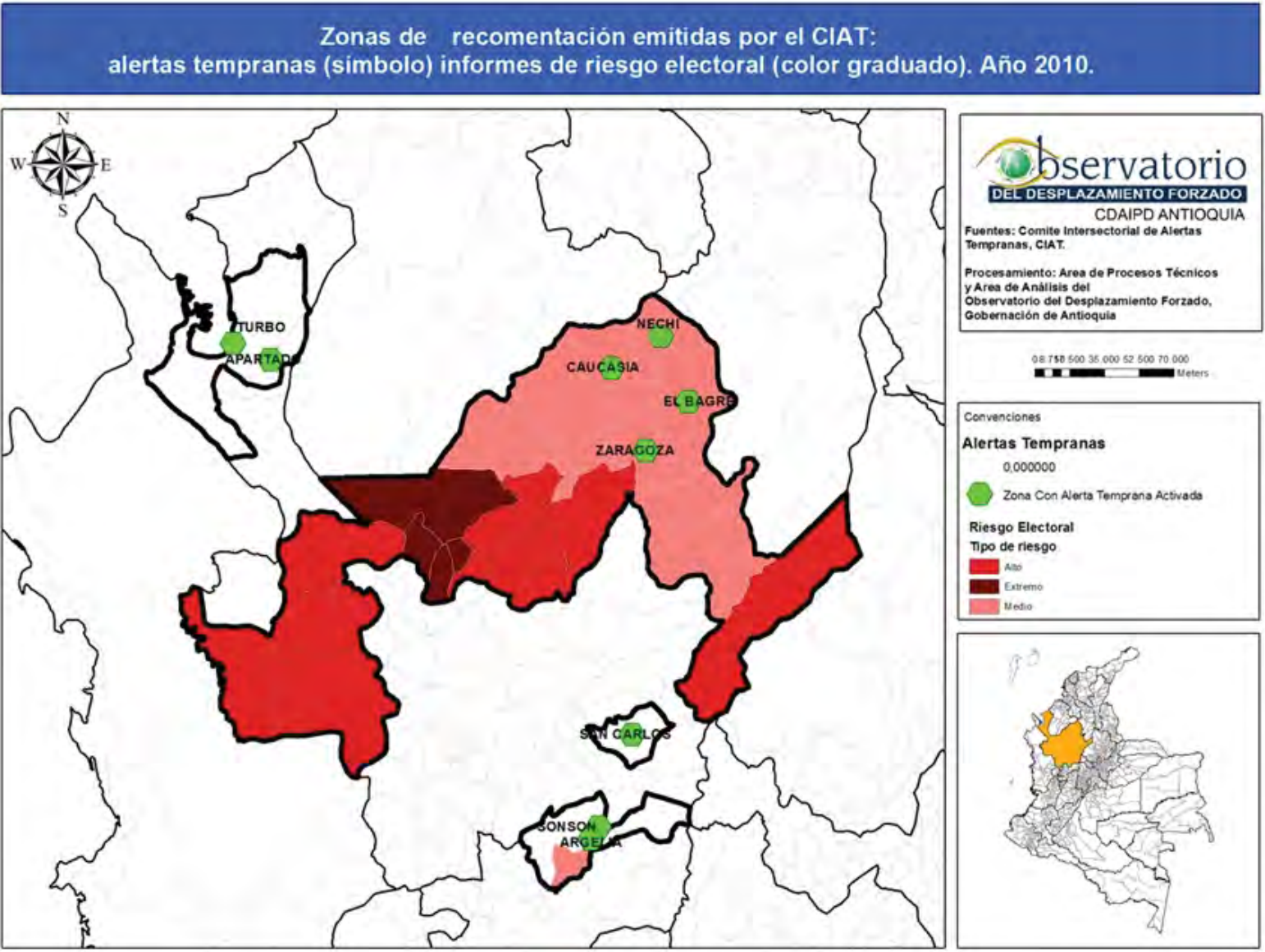

MAPA 01: Departamento de Antioquia. Zonas de recomendación de Alertas Tempranas e Informes de Riesgo Electoral emitidas por el CIAT. Procesado Oddif, julio 2010. 
A partir de los municipios comprendidos en estas alertas e informes se definió como Zona CIAT la siguiente regionalización de Antioquia, ilustrado en el siguiente mapa.

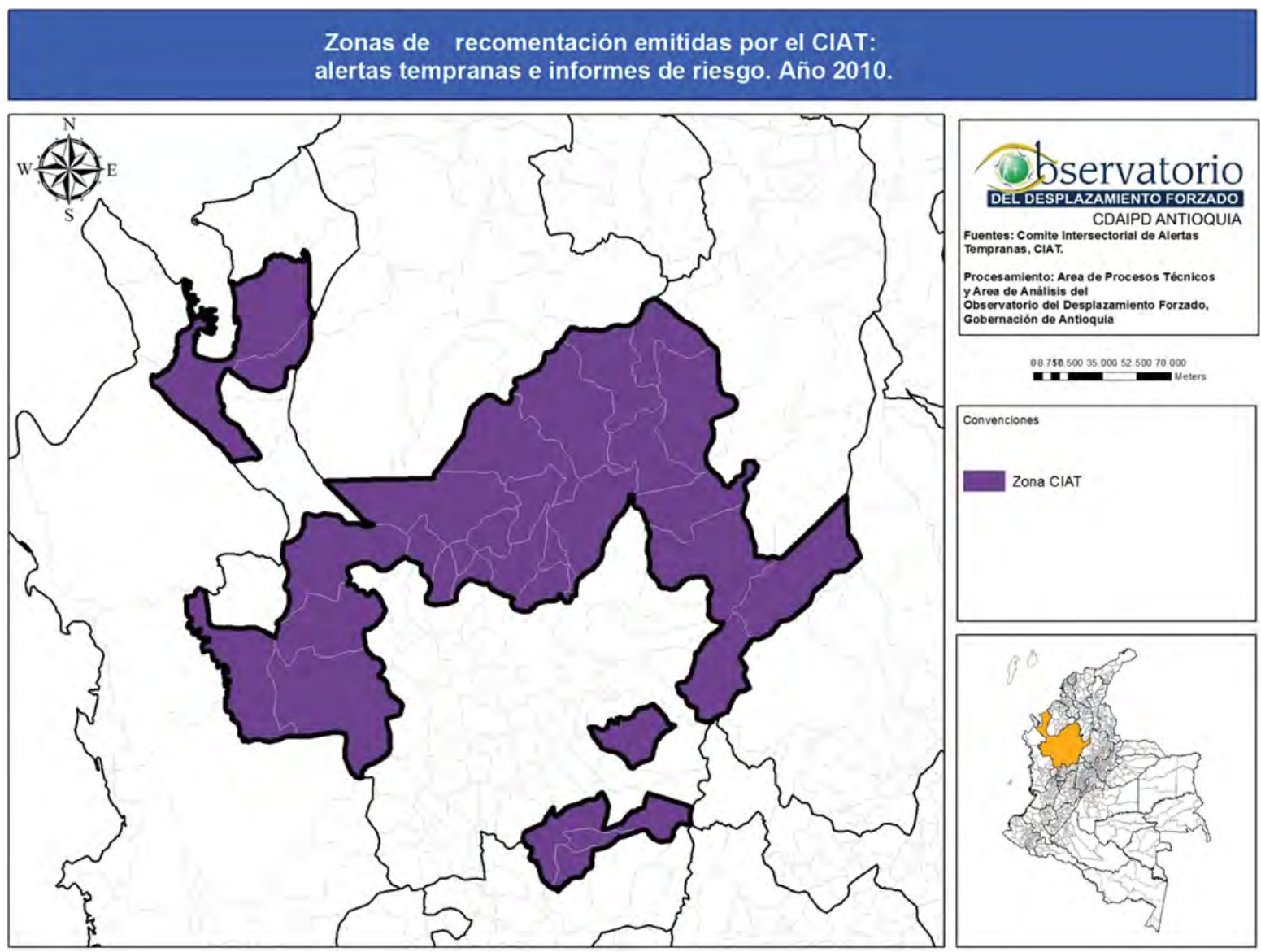

MAPA 01: Departamento de Antioquia. Zona CIAT. Procesado Oddif, julio 2010.

La continuidad que puede establecerse en una gran extensión de la Zona CIAT va de Oriente a Occidente, y presenta como zonas externas dos municipios de la zona central del Urabá y cuatro del Oriente antioqueño. Los siguientes mapas dan cuenta de las acciones armadas de grupos armados ilegales y las de iniciativa de la Fuerza Pública en Antioquia, durante la última década. Aquí se destaca la presencia de estas acciones en la Zona CIAT.

Los siguientes son los indicadores de prevención (homicidios, acciones armadas, eventos por Minas Antipersona) medidos en la Zona CIAT.

\section{Resultados-discusiones.}

Impactos territoriales de homicidios, acciones armadas y minas antipersona en zonas con recomendaciones emitidas por el CIAT.

240

AGO.USB Medellín-Colombia $\quad$ V. 12 №2 PP. 214- 547 Julio-Diciembre 2012 ISSN: 1657-8031 
En esta sección serán presentados tres indicadores (homicidios, acciones armadas y accidentes e incidentes por minas antipersona, MAP) cuya fuente proviene de la base de datos sobre conflicto armado procesada por el Observatorio de DD.HH de la vicepresidencia de la república.

La siguiente gráfica expresa los totales anuales de homicidios en la zona de estudio. Tras el pico vivido a comienzo de la década, se observa una notable disminución de homicidios que -tras un relativo equilibrio en el quinquenio 2004-2008-aumentan para el año 2009.

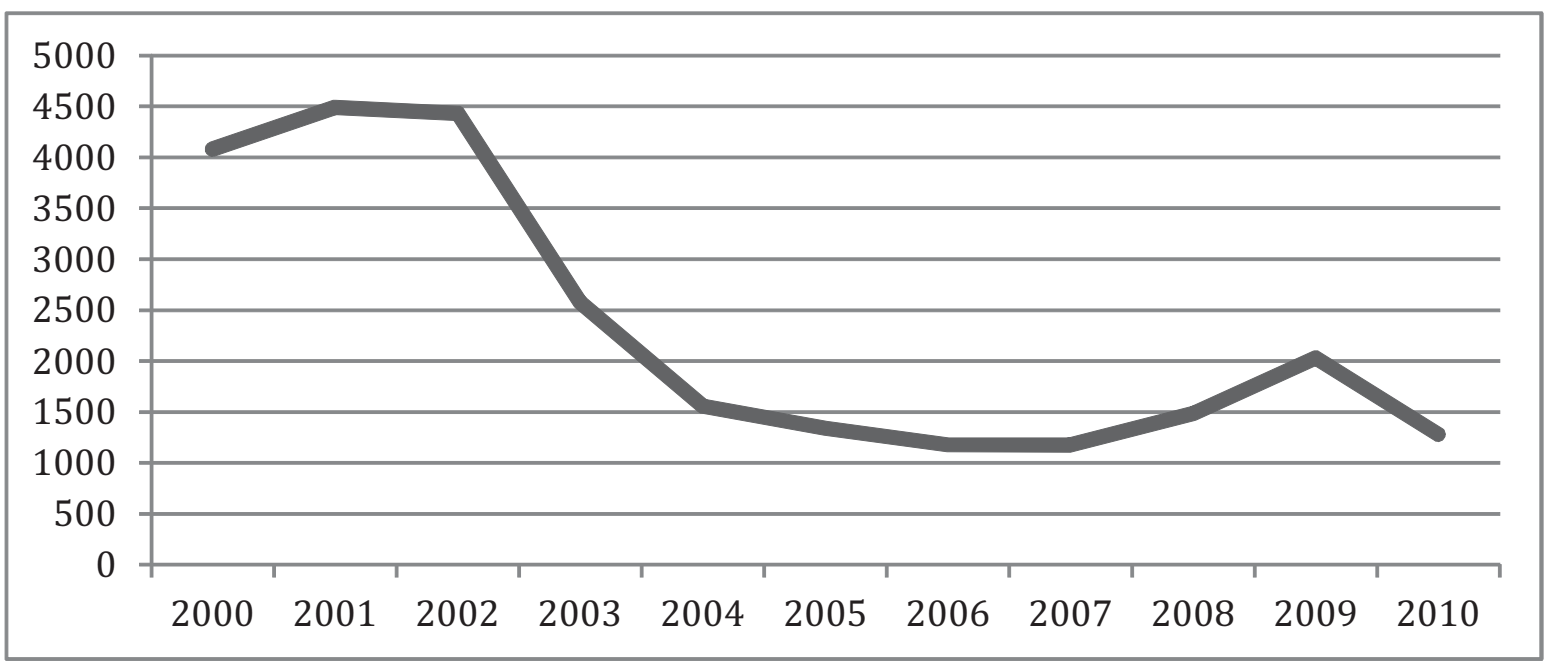

Figura 01: Departamento de Antioquia. Número de homicidios en municipios con informe de riesgo SAT años 2000 a 2010. Fuente: Estadísticas del Observatorio de DD. HH. y DIH Vicepresidencia de la República. Procesado Oddif, julio 2010.

Los siguientes mapas que dan cuenta del comportamiento territorial de los homicidios ocurridos, año tas año desde el año 2000, en los municipios ubicados en esta zona. La máxima intensidad de color señala los números máximos de homicidios anuales en cada municipio. 

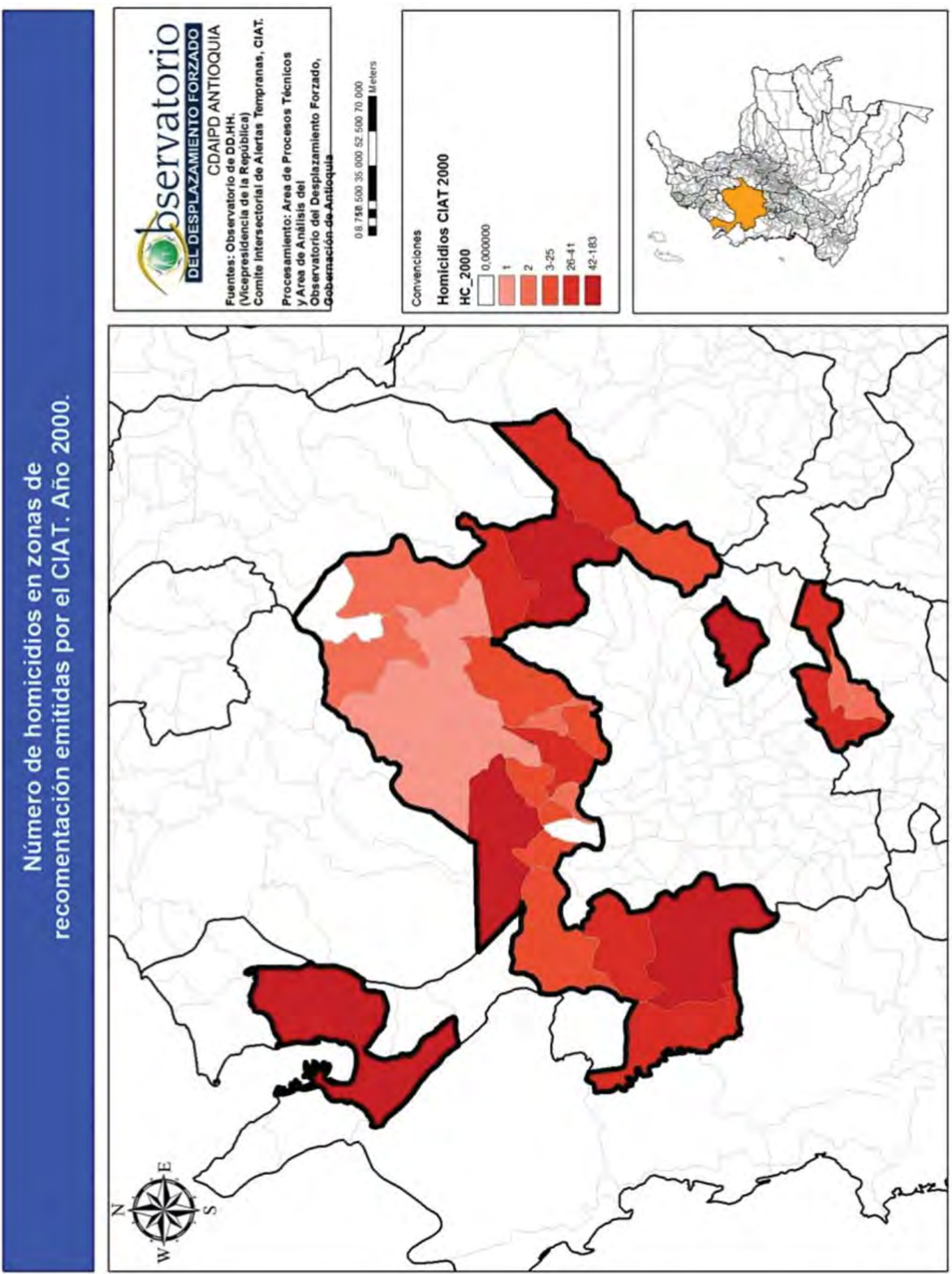

MAPA 03: Departamento de Antioquia. Número de homicidios en municipios con informe de riesgo SAT año 2000 Fuente: Estadísticas del Observatorio de DD. HH. y DIH Vicepresidencia de la República. Procesado Oddif, julio. 2010. 
Factores de Riesgo para el Desplazamiento, Protección de Tierras y Garantias de no Repetición en Zonas Vulnerables de Antioquia.

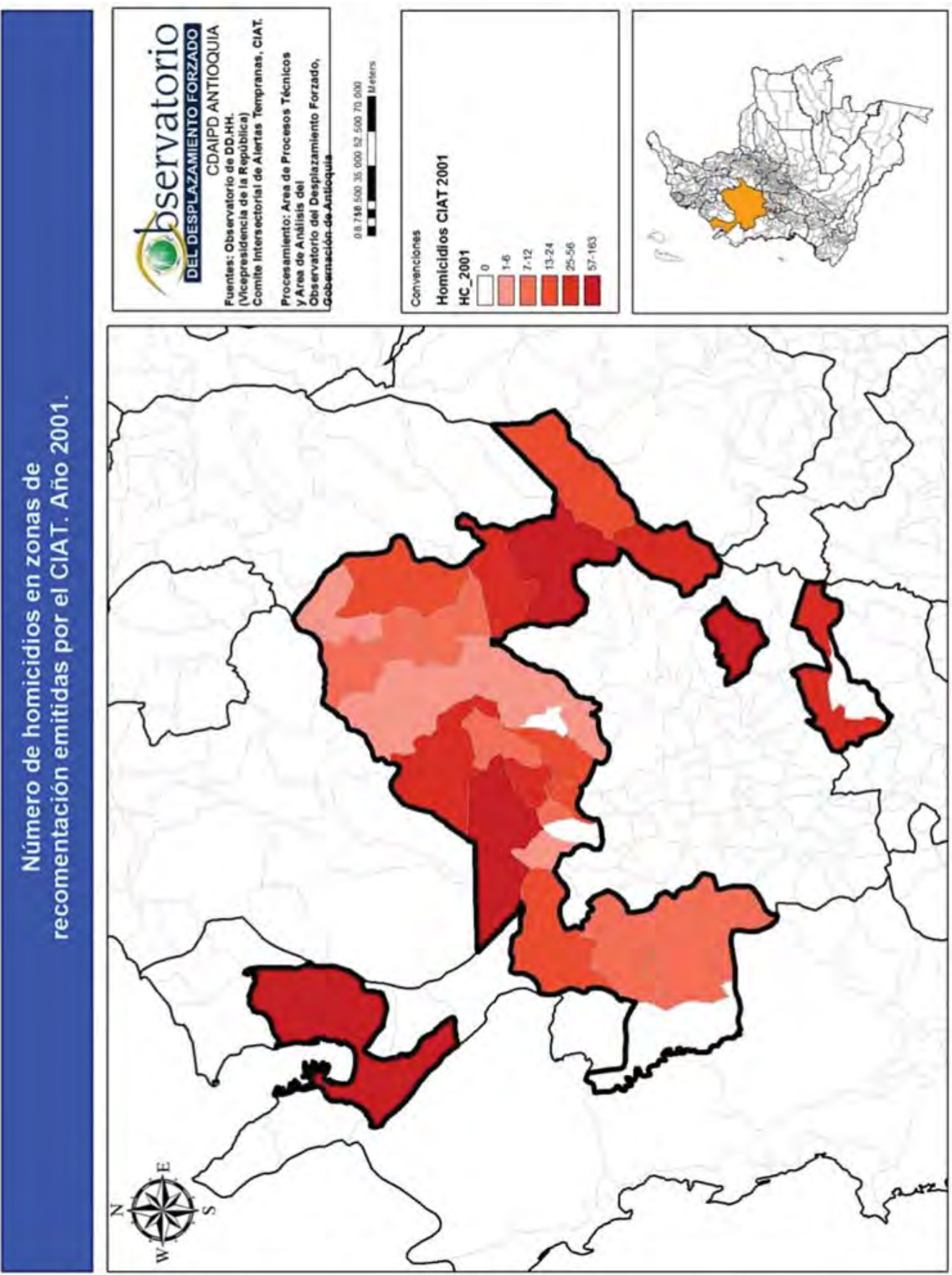

MAPA 04: Departamento de Antioquia. Número de homicidios en municipios con informe de riesgo SAT año 2001 Fuente: Estadísticas del Observatorio de DD. HH. y DIH Vicepresidencia de la República. Procesado Oddif, julio 2010. 
Factores de Riesgo para el Desplazamiento, Protección de Tierras y Garantias de no Repetición en Zonas Vulnerables de Antioquia.

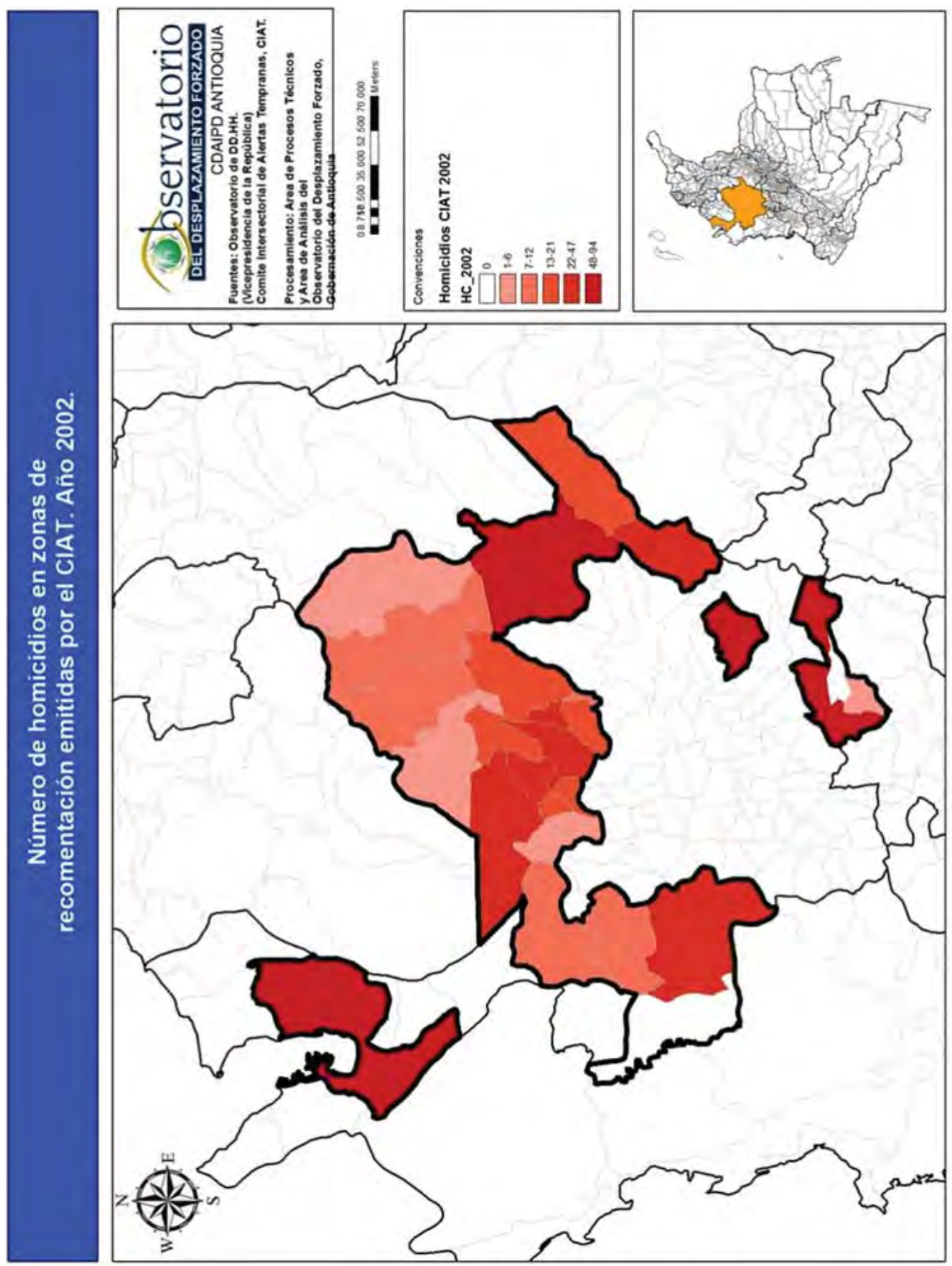

MAPA 05: Departamento de Antioquia. Número de homicidios en municipios con informe de riesgo SAT año 2002 Fuente: Estadísticas del Observatorio de DD. HH. y DIH Vicepresidencia de la República. Procesado Oddif, julio 2010. 
Factores de Riesgo para el Desplazamiento, Protección de Tierras y Garantias de no Repetición en Zonas Vulnerables de Antioquia.

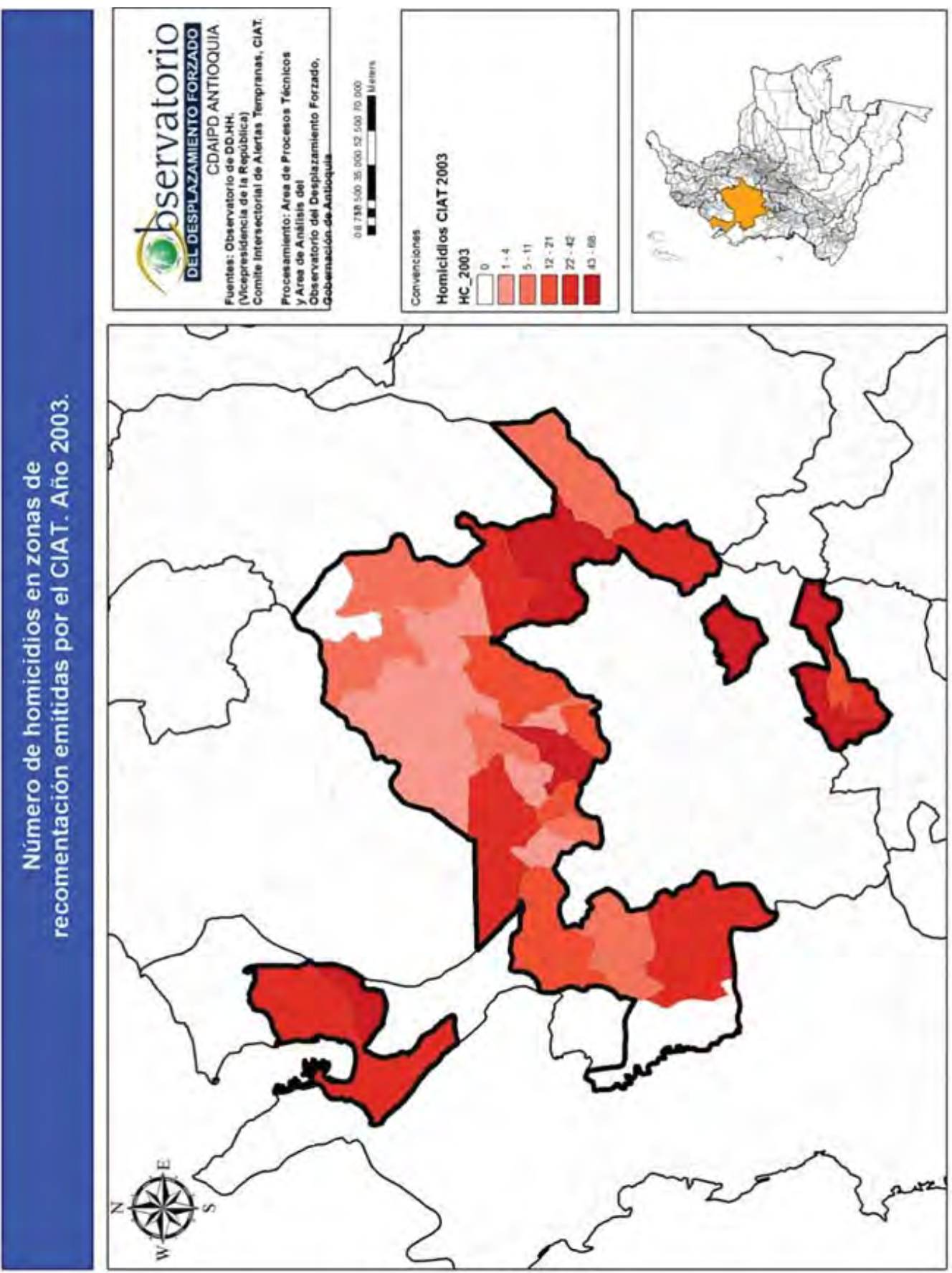

MAPA 06: Departamento de Antioquia. Número de homicidios en municipios con informe de riesgo SAT año 2003 Fuente: Estadísticas del Observatorio de DD. HH. y DIH Vicepresidencia de la República. Procesado Oddif, julio 2010. 
Factores de Riesgo para el Desplazamiento, Protección de Tierras y Garantias de no Repetición en Zonas Vulnerables de Antioquia.

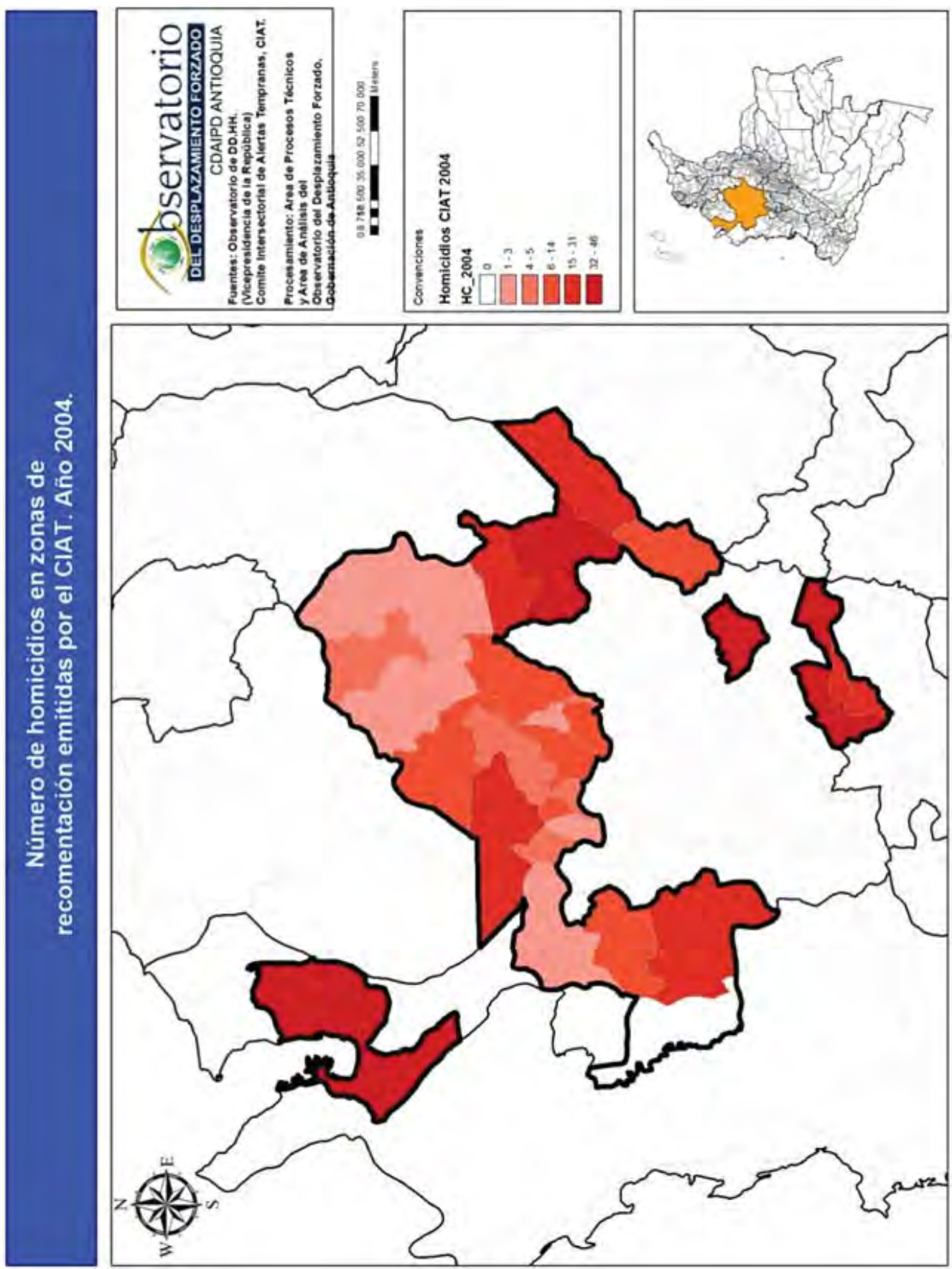

MAPA 07: Departamento de Antioquia. Número de homicidios en municipios con informe de riesgo SAT año 2004 Fuente: Estadísticas del Observatorio de DD. HH. y DIH Vicepresidencia de la República. Procesado Oddif, julio 2010. 
Factores de Riesgo para el Desplazamiento, Protección de Tierras y Garantias de no Repetición en Zonas Vulnerables de Antioquia.

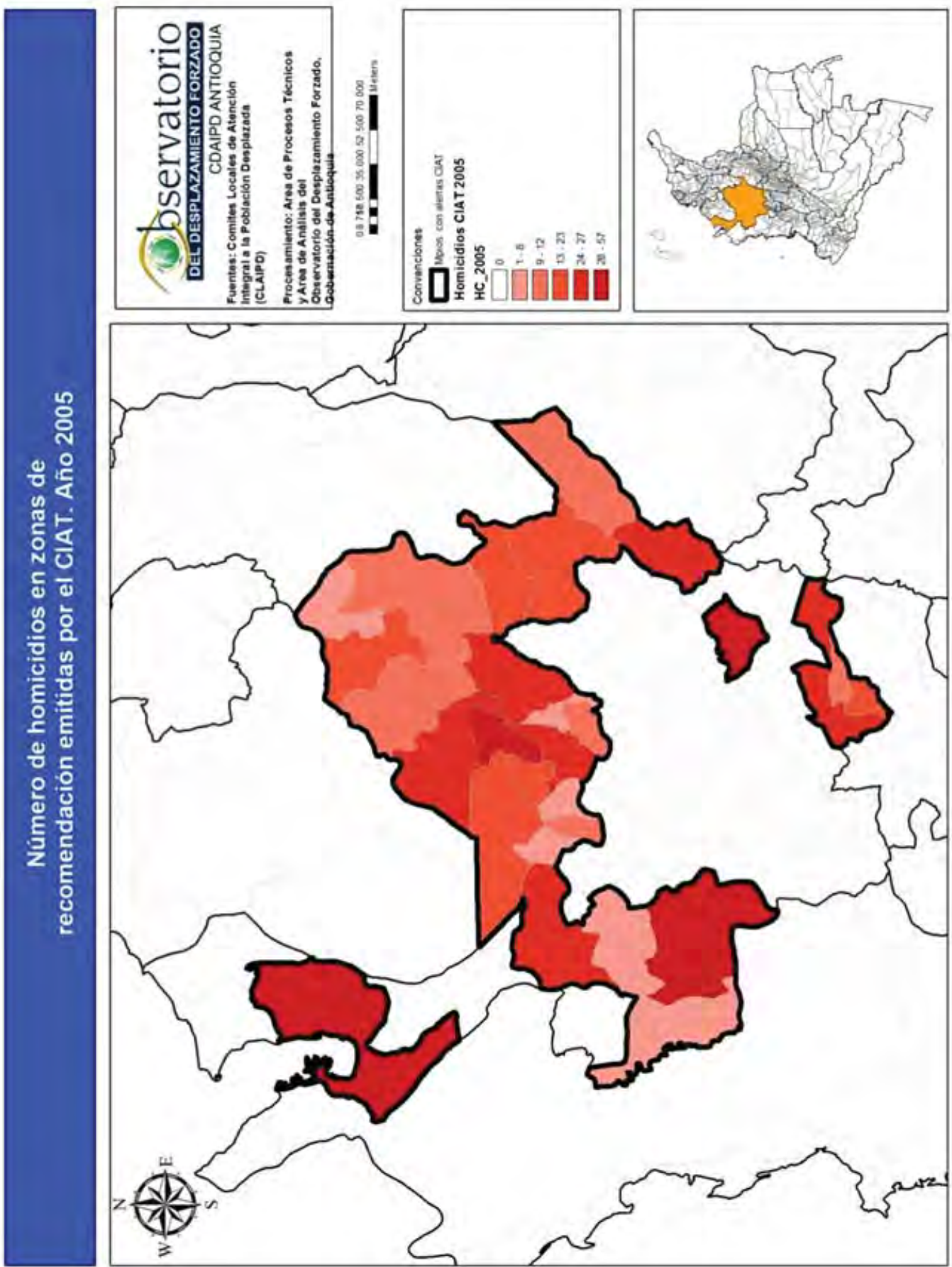

MAPA 08: Departamento de Antioquia. Número de homicidios en municipios con informe de riesgo SAT año 2005 Fuente: Estadísticas del Observatorio de DD. HH. y DIH Vicepresidencia de la República. Procesado Oddif, julio 2010. 


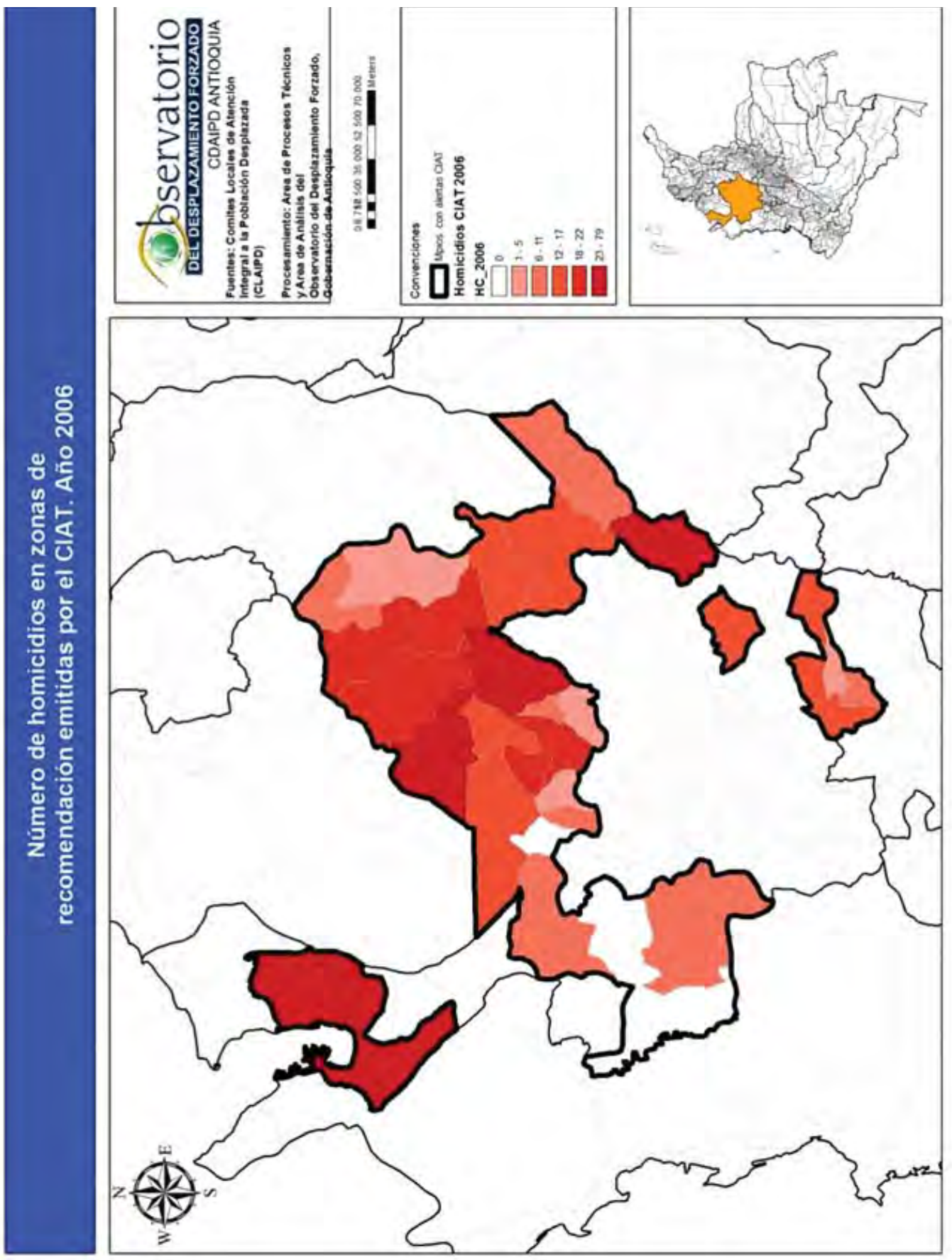

MAPA 09: Departamento de Antioquia. Número de homicidios en municipios con informe de riesgo SAT año 2006 Fuente: Estadísticas del Observatorio de DD. HH. y DIH Vicepresidencia de la República. Procesado Oddif, julio 2010. 
Factores de Riesgo para el Desplazamiento, Protección de Tierras y Garantias de no Repetición en Zonas Vulnerables de Antioquia.

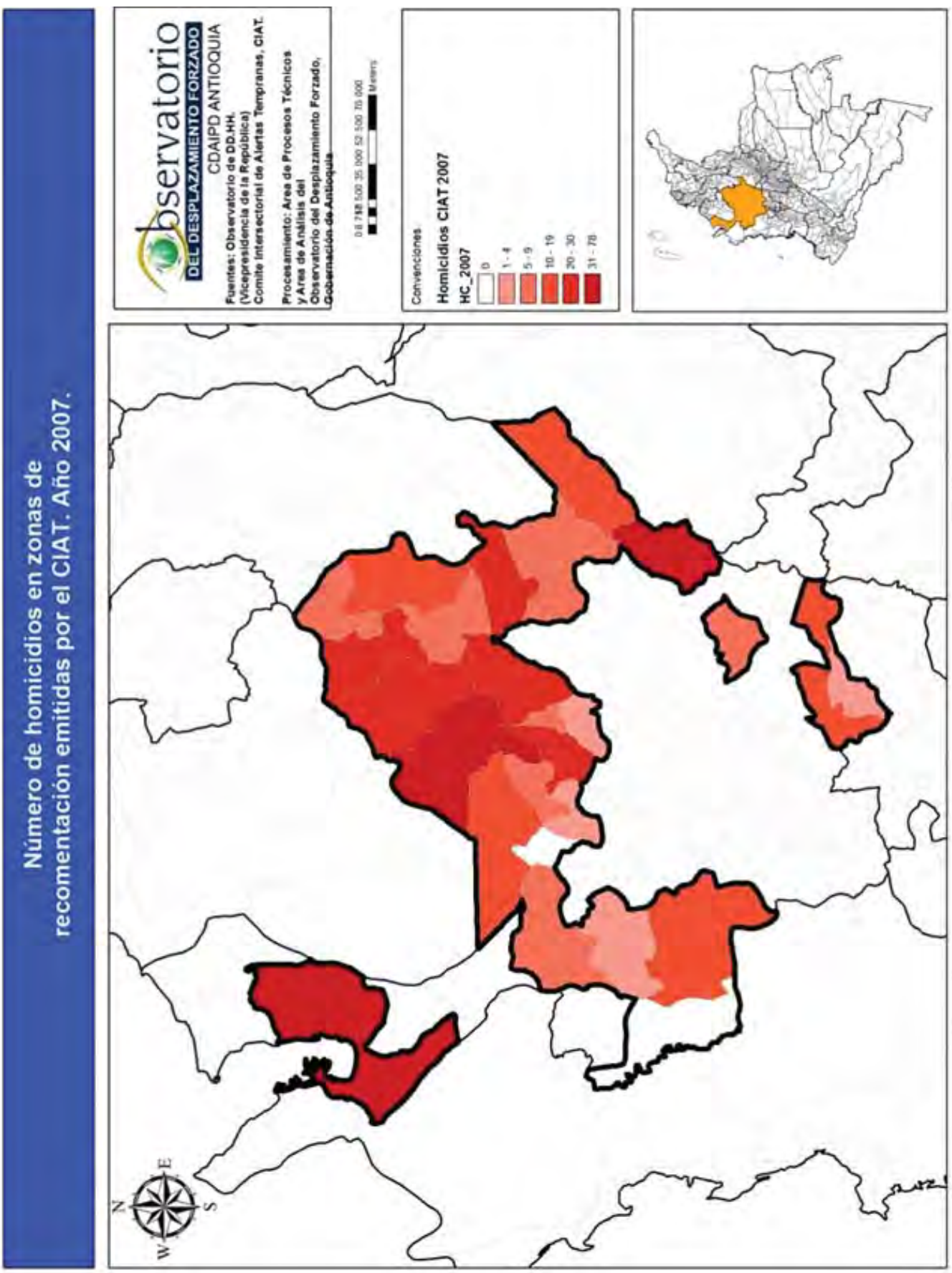

MAPA 10: Departamento de Antioquia. Número de homicidios en municipios con informe de riesgo SAT año 2007 Fuente: Estadísticas del Observatorio de DD. HH. y DIH Vicepresidencia de la República. Procesado Oddif, julio 2010. 
Factores de Riesgo para el Desplazamiento, Protección de Tierras y Garantias de no Repetición en Zonas Vulnerables de Antioquia.

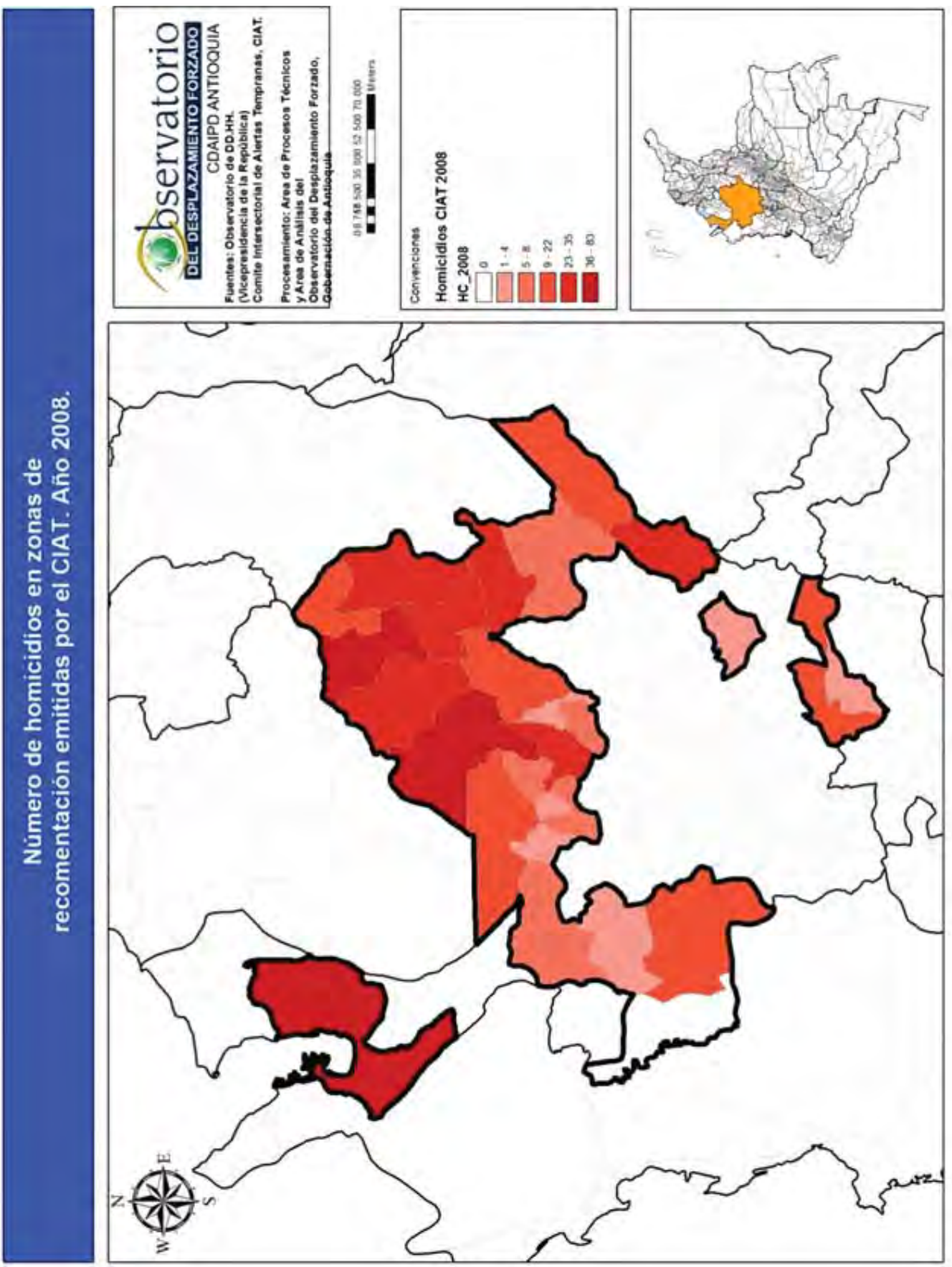

MAPA 11: Departamento de Antioquia. Número de homicidios en municipios con informe de riesgo SAT año 2008 Fuente: Estadísticas del Observatorio de DD. HH. y DIH Vicepresidencia de la República. Procesado Oddif, julio 2010. 
Factores de Riesgo para el Desplazamiento, Protección de Tierras y Garantias de no Repetición en Zonas Vulnerables de Antioquia.

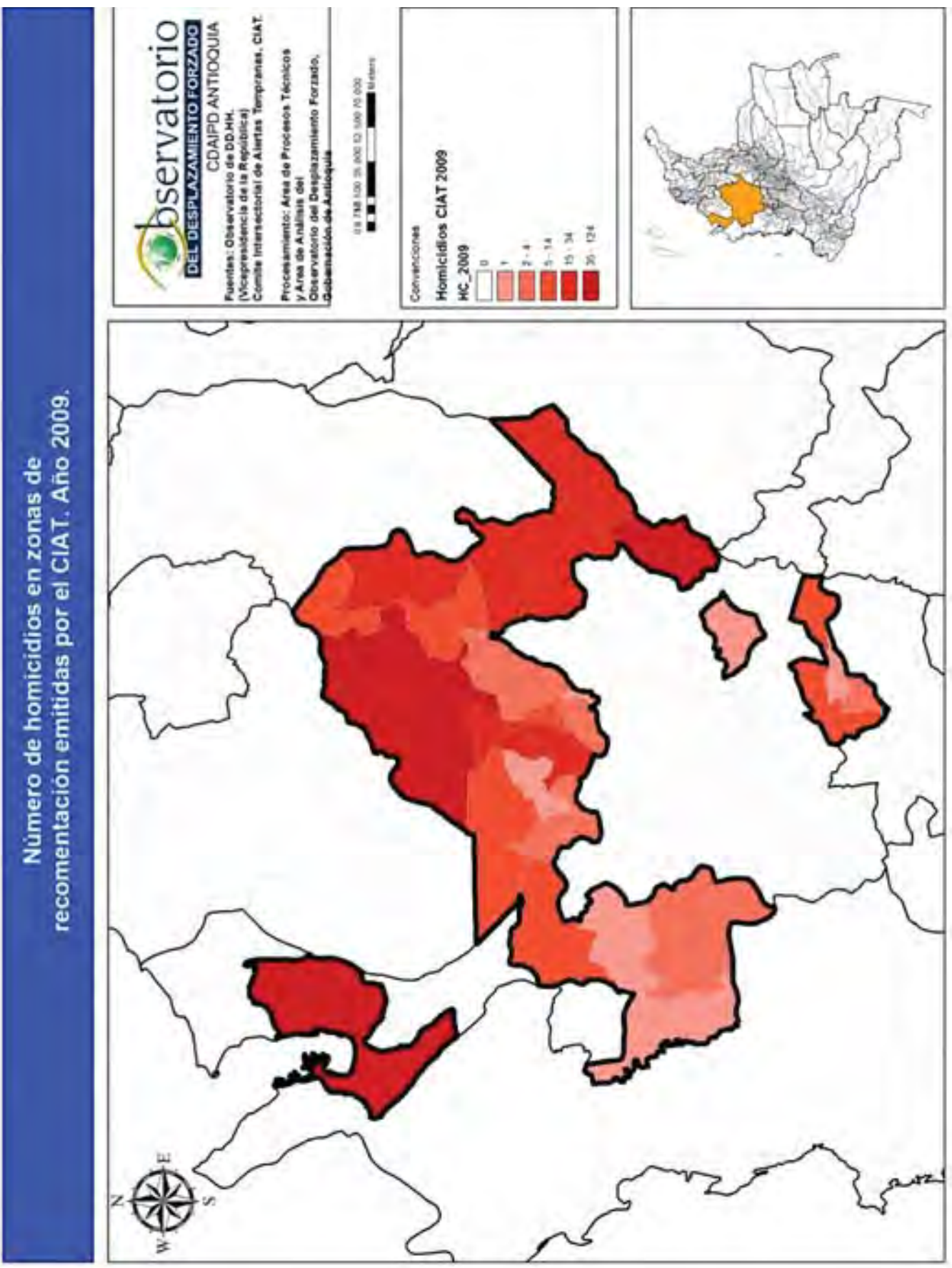

MAPA 12: Departamento de Antioquia. Número de homicidios en municipios con informe de riesgo SAT año 2009 Fuente: Estadísticas del Observatorio de DD. HH. y DIH Vicepresidencia de la República. Procesado Oddif, julio 2010. 


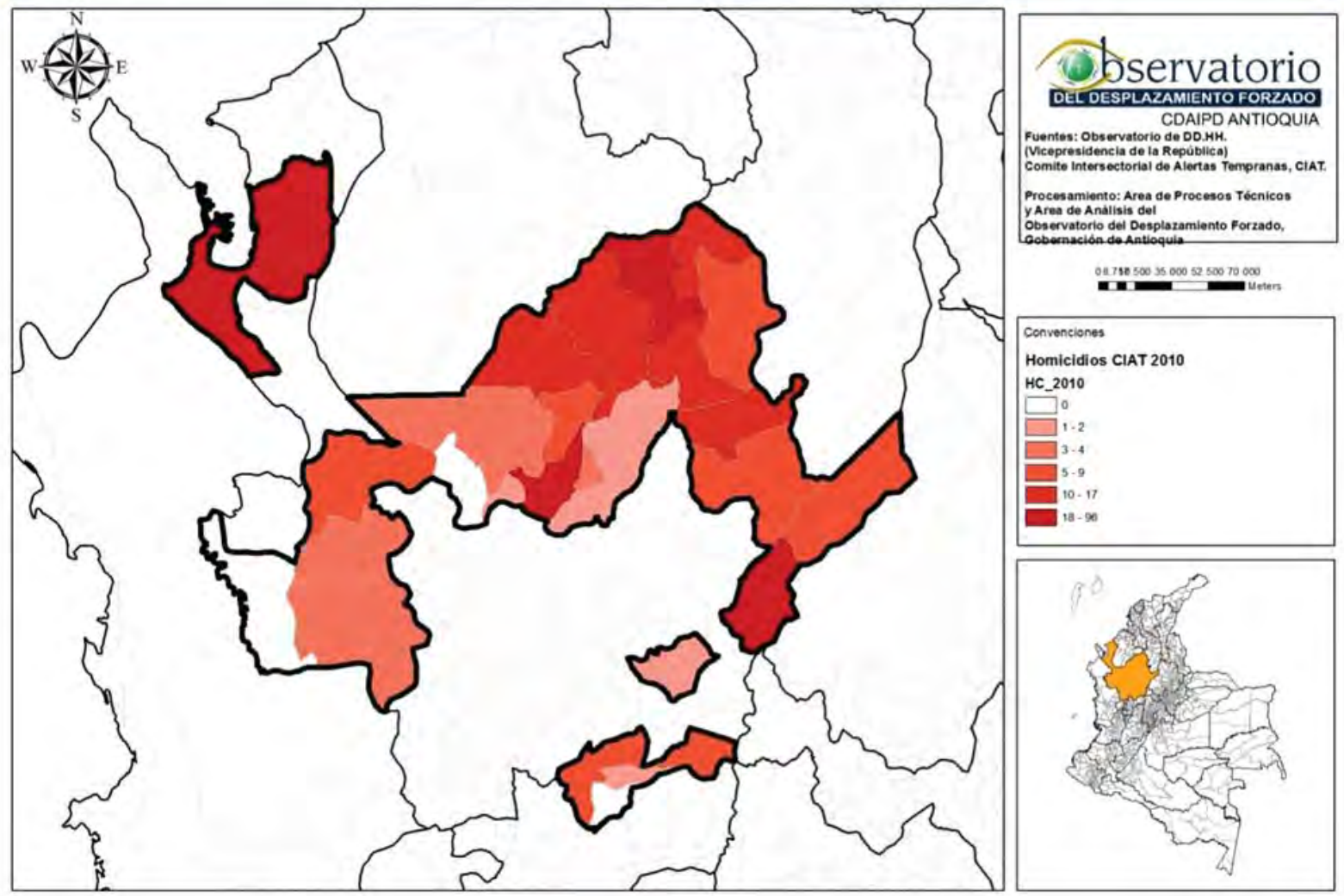

MAPA 13: Departamento de Antioquia. Número de homicidios en municipios con informe de riesgo SAT año 2010 Fuente: Estadísticas del Observatorio de DD. HH. y DIH Vicepresidencia de la República. Procesado Oddif, julio 2010.

La situación, aunque pareciera demostrar un comportamiento homogéneo a lo largo de la zona CIAT, destaca varias cosas:

- Los municipios del Urabá sostienen, a lo largo de la serie, la más alta intensidad.

- Los municipios del Oriente antioqueño expresan un descenso en la intensidad del fenómeno hacia el final de la serie.

- La zona Norte del área CIAT (Bajo Cauca) incrementa gradualmente la intensidad de los homicidios a lo largo de la serie, hasta llegar a comprender la sección que concentra la más alta intensidad.

Acciones de grupos armados ilegales y acciones por iniciativa de la fuerza pública en zonas con recomendaciones emitidas por el CIAT.

(252 AGO.USB Medellín-Colombia V. 12 N 2 PP. 214- 547 Julio-Diciembre 2012 ISSN: 1657-8031 
Las siguientes gráficas y la serie de mapas que a continuación se presentan dan cuenta de la relación entre acciones armadas de grupos al margen de la ley y aquellas que han sido iniciativa de la fuerza pública.

El comportamiento de ambas variables da cuenta de la relación inversamente proporcional de las acciones: cuando son mayores las acciones por iniciativa de la fuerza pública, menores las de los grupos al margen de la ley y viceversa. Esta tendencia puede apreciarse, de manera particular, en los años 2003-2008, y 2009-2010.

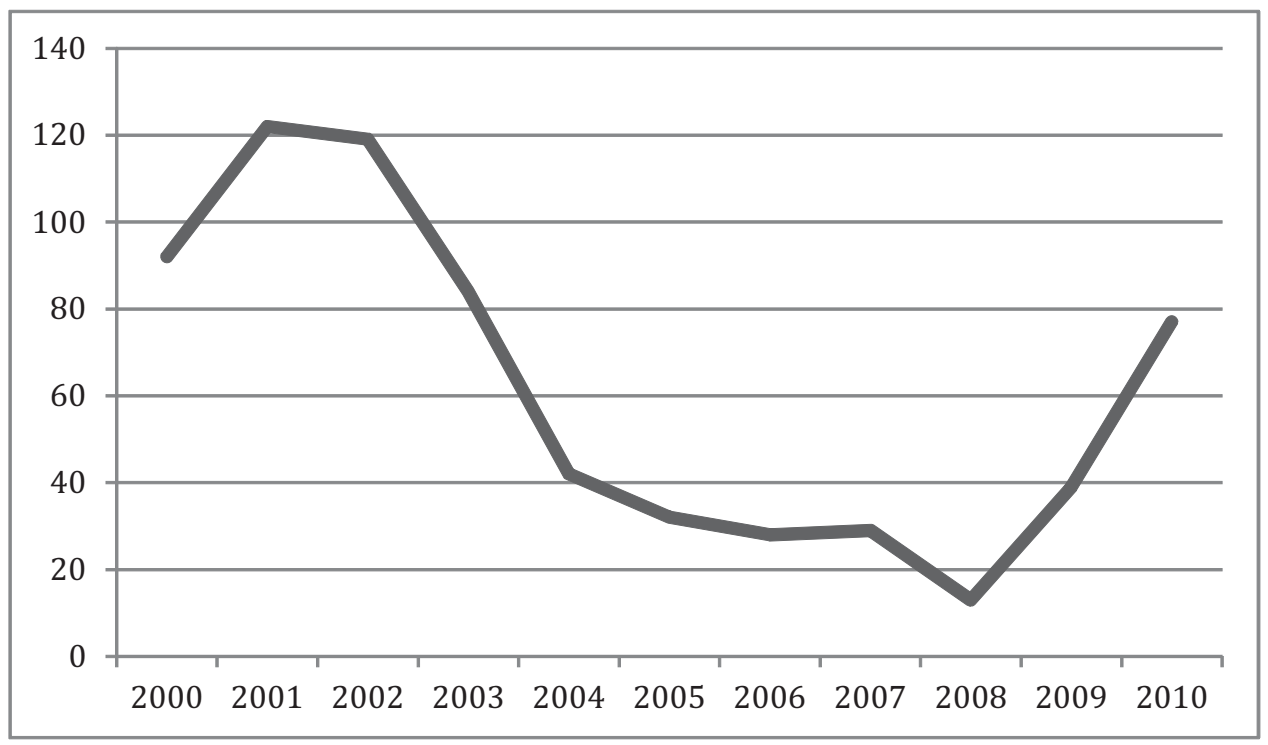

Figura 02: Departamento de Antioquia. Número de acciones de grupos armados ilegales en municipios con informe de riesgo SAT, años 2000 a 2010. Fuente: Estadísticas del Observatorio de DD. HH. y DIH Vicepresidencia de la República. Procesado Oddif, julio 2010.

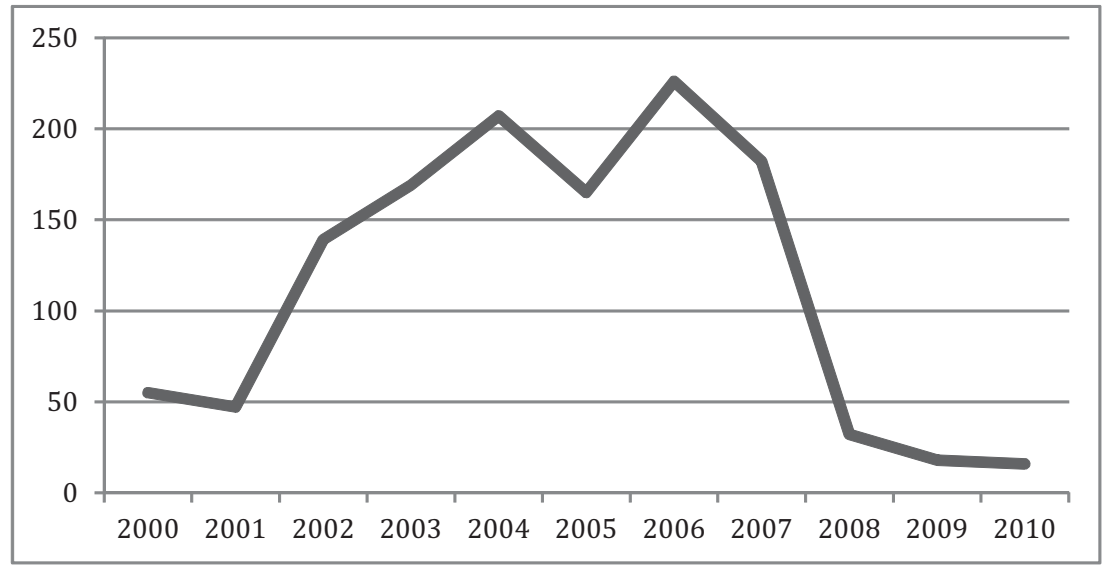

Figura 03: Departamento de Antioquia. Contactos armados de la fuerza pública contra grupos armados al margen de la ley. Años 2000 a 2010. Fuente: Estadísticas del Observatorio de DD. HH. y DIH Vicepresidencia de la República. Procesado Oddif, julio 2010. 
Los mapas siguientes dan cuenta de la expresión territorial de estas variables.
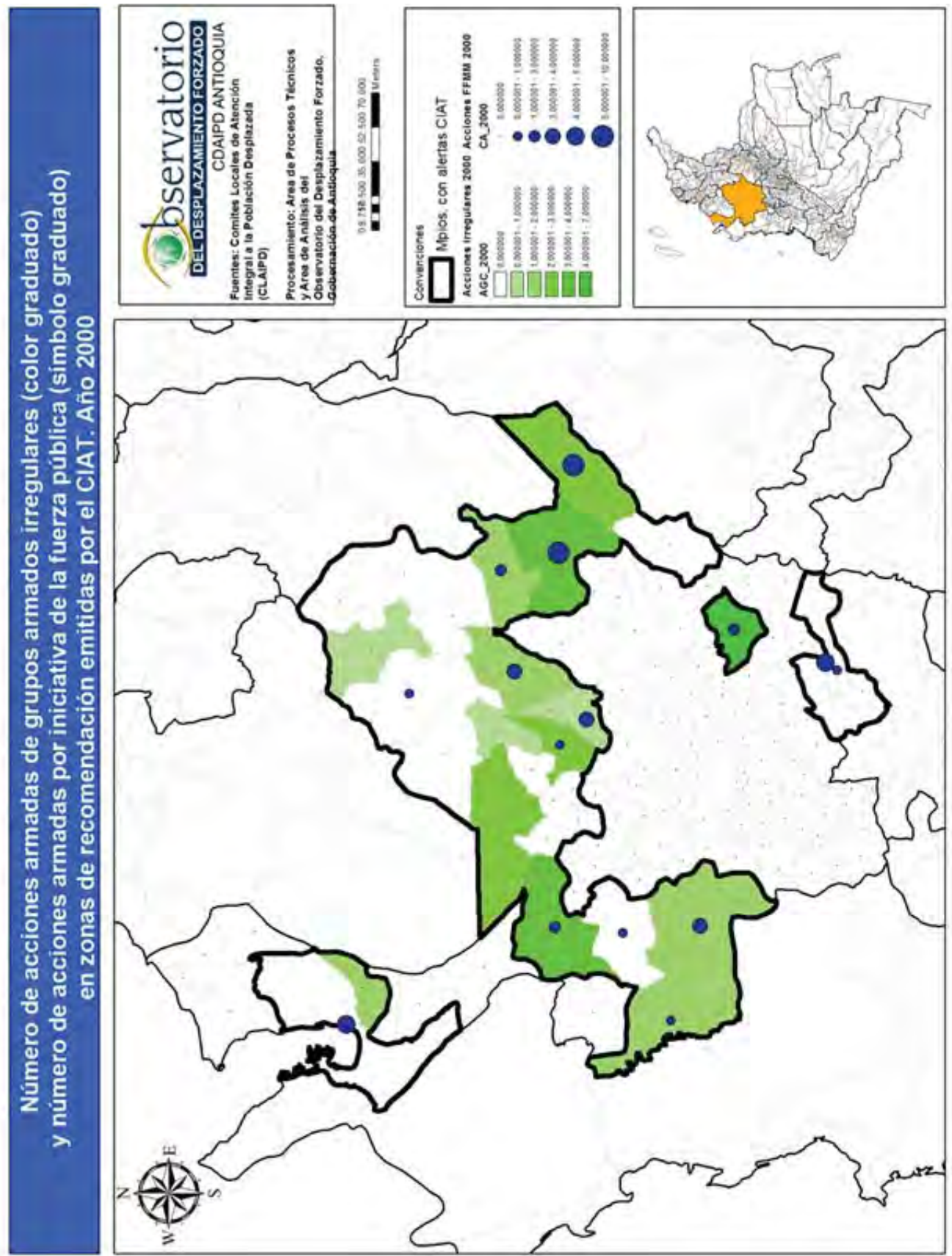

MAPA 14: Departamento de Antioquia. Número de acciones armadas de grupos al margen de la ley y por inciiativa de la fuerza pública en la Zona CIAT 2000. Fuente: Estadísticas del Observatorio de DD. HH. y DIH Vicepresidencia de la República. Procesado Oddif, julio 2010.

5254 AGo.USB Medellín-Colombia $\quad$ V. $12 \quad N^{\circ} 2 \quad$ PP. 214- 547 Julio-Diciembre 2012 ISSN: 1657-8031 
Factores de Riesgo para el Desplazamiento, Protección de Tierras y Garantias de no Repetición en Zonas Vulnerables de Antioquia.

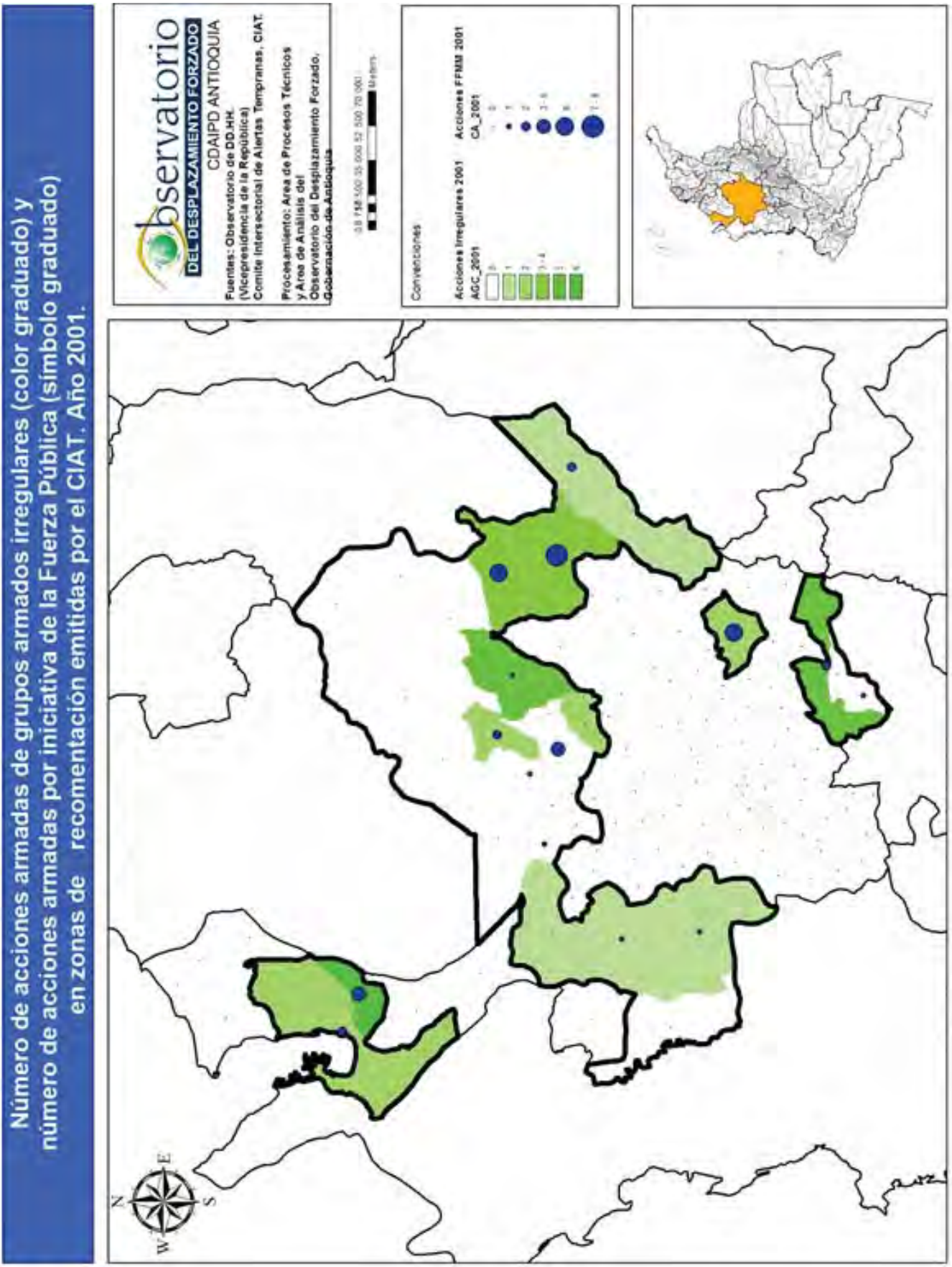

MAPA 15: Departamento de Antioquia. Número de acciones armadas de grupos al margen de la ley y por inciiativa de la fuerza pública en la Zona CIAT 2001. Fuente: Estadísticas del Observatorio de DD. HH. y DIH Vicepresidencia de la República. Procesado Oddif, julio 2010. 
Factores de Riesgo para el Desplazamiento, Protección de Tierras y Garantias de no Repetición en Zonas Vulnerables de Antioquia.

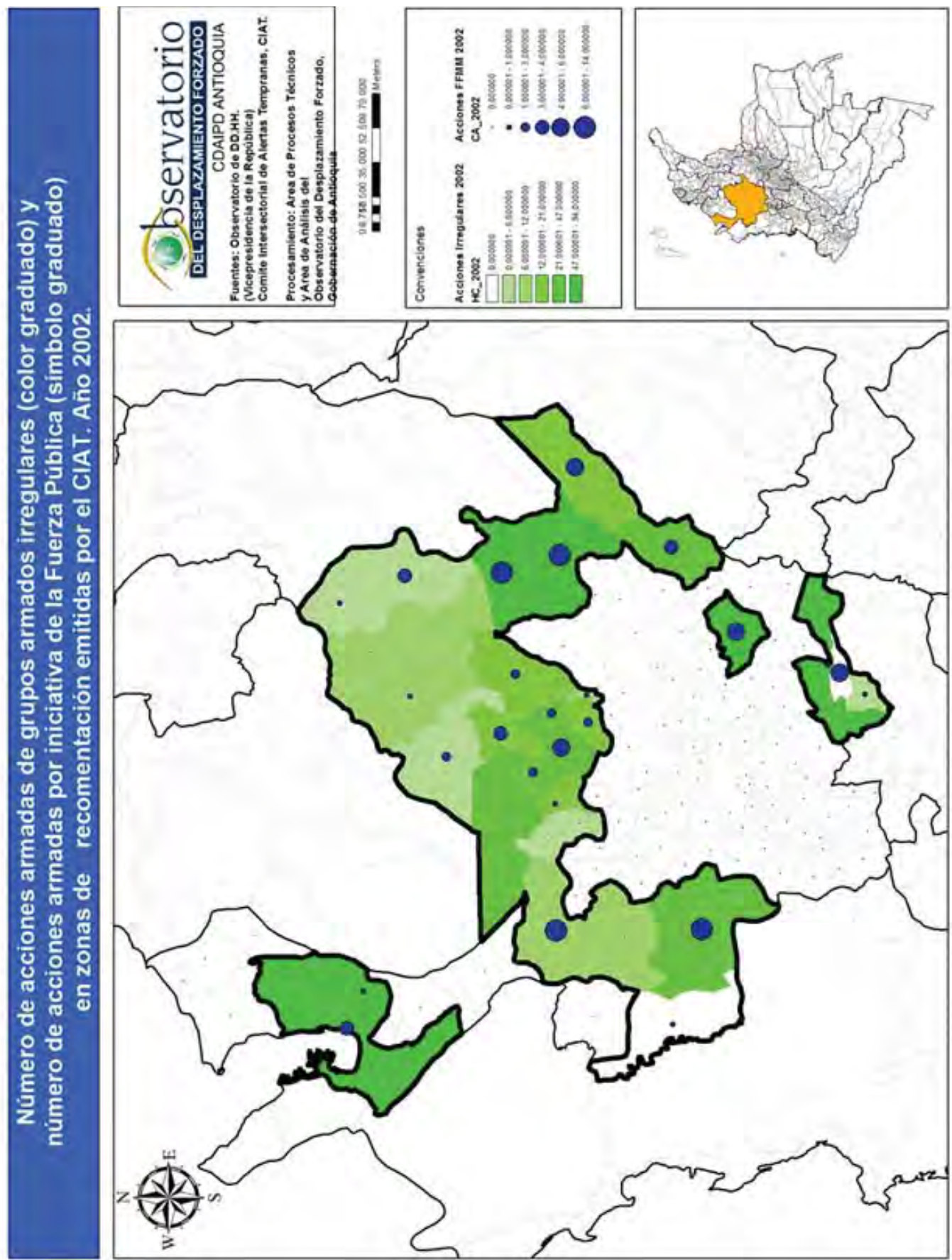

MAPA 16: Departamento de Antioquia. Número de acciones armadas de grupos al margen de la ley y por inciiativa de la fuerza pública en la Zona CIAT 2002. Fuente: Estadísticas del Observatorio de DD. HH. y DIH Vicepresidencia de la República. Procesado Oddif, julio 2010. 
Factores de Riesgo para el Desplazamiento, Protección de Tierras y Garantias de no Repetición en Zonas Vulnerables de Antioquia.

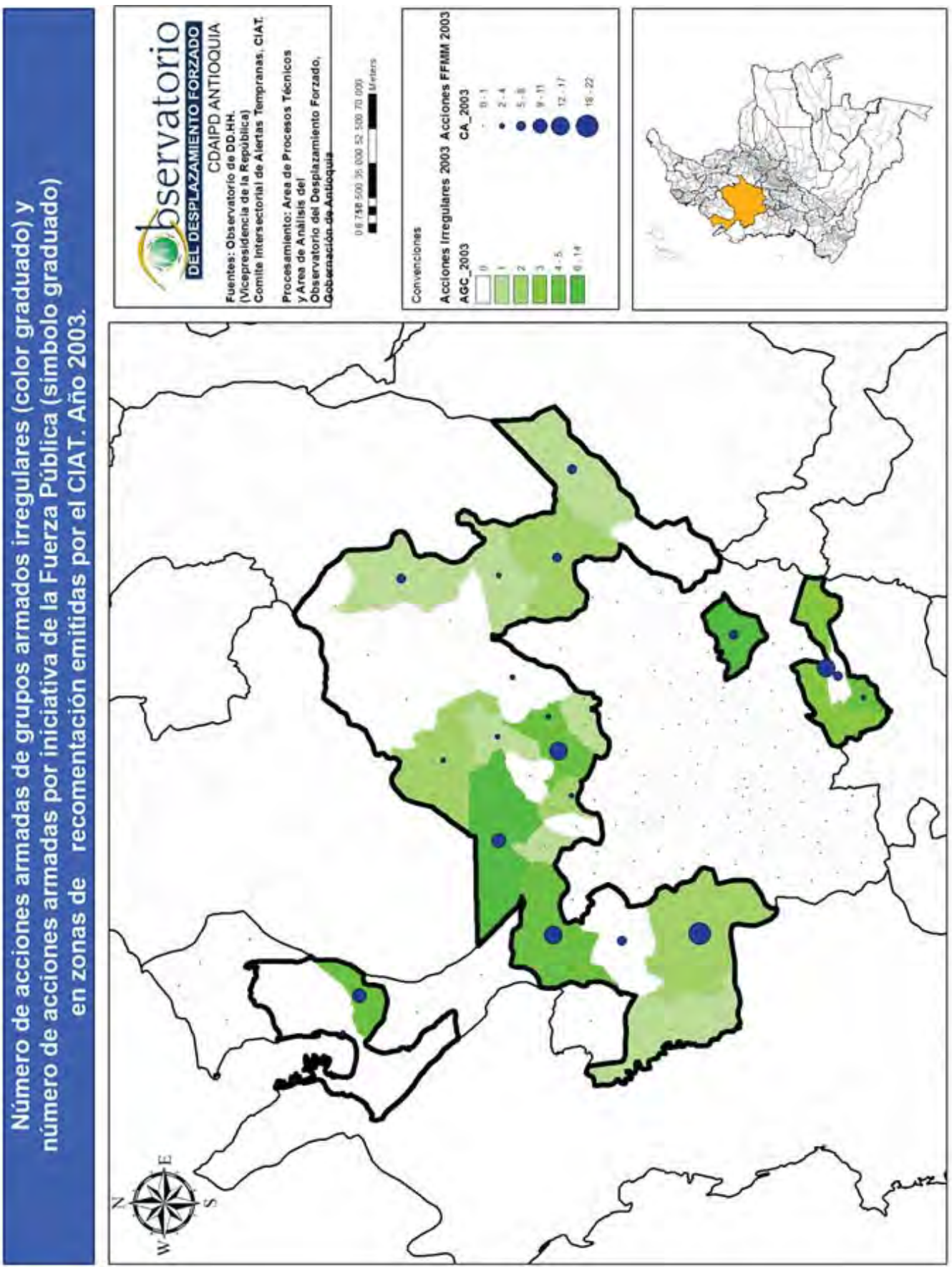

MAPA 17: Departamento de Antioquia. Número de acciones armadas de grupos al margen de la ley y por inciiativa de la fuerza pública en la Zona CIAT 2003. Fuente: Estadísticas del Observatorio de DD. HH. y DIH Vicepresidencia de la República. Procesado Oddif, julio 2010. 
Factores de Riesgo para el Desplazamiento, Protección de Tierras y Garantias de no Repetición en Zonas Vulnerables de Antioquia.

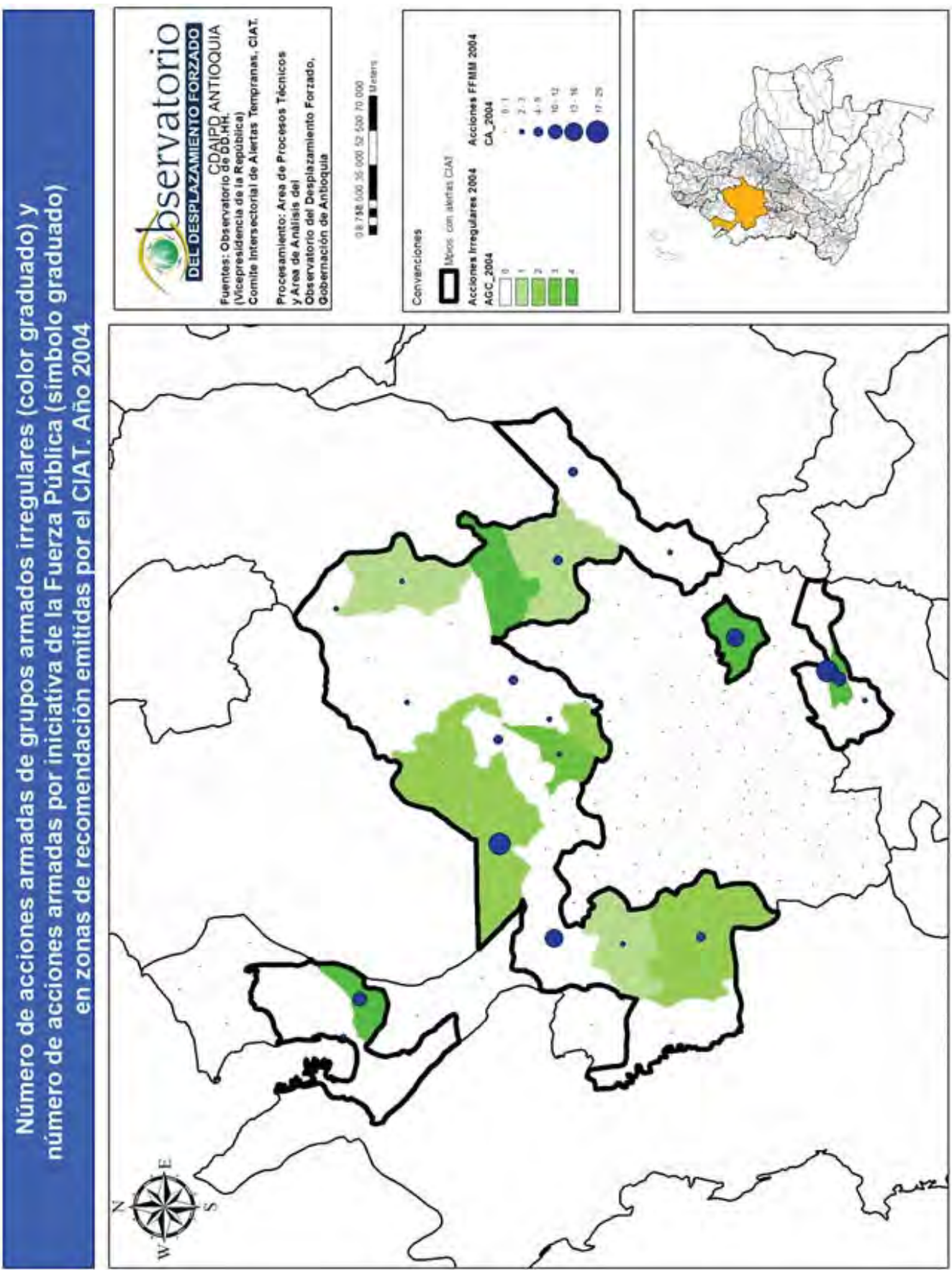

MAPA 18: Departamento de Antioquia. Número de acciones armadas de grupos al margen de la ley y por inciiativa de la fuerza pública en la Zona CIAT 2004. Fuente: Estadísticas del Observatorio de DD. HH. y DIH Vicepresidencia de la República. Procesado Oddif, julio 2010.

258

AGO.USB Medellín-Colombia V. $12 \quad N^{\circ} 2$ PP. 214- 547 Julio-Diciembre 2012 ISSN: 1657-8031 
Factores de Riesgo para el Desplazamiento, Protección de Tierras y Garantias de no Repetición en Zonas Vulnerables de Antioquia.

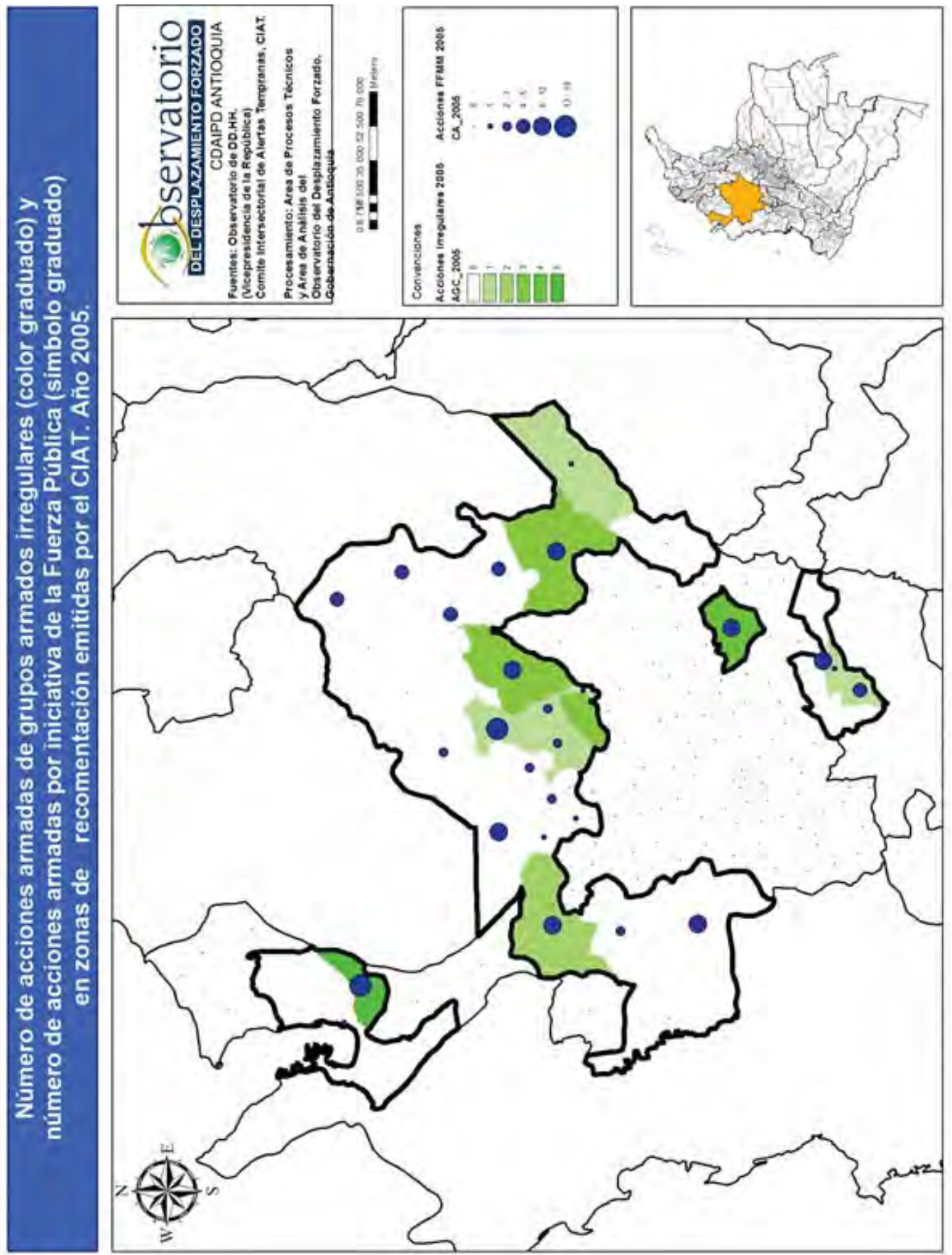

MAPA 19: Departamento de Antioquia. Número de acciones armadas de grupos al margen de la ley y por inciiativa de la fuerza pública en la Zona CIAT 2005. Fuente: Estadísticas del Observatorio de DD. HH. y DIH Vicepresidencia de la República. Procesado Oddif, julio 2010. 
Factores de Riesgo para el Desplazamiento, Protección de Tierras y Garantias de no Repetición en Zonas Vulnerables de Antioquia.

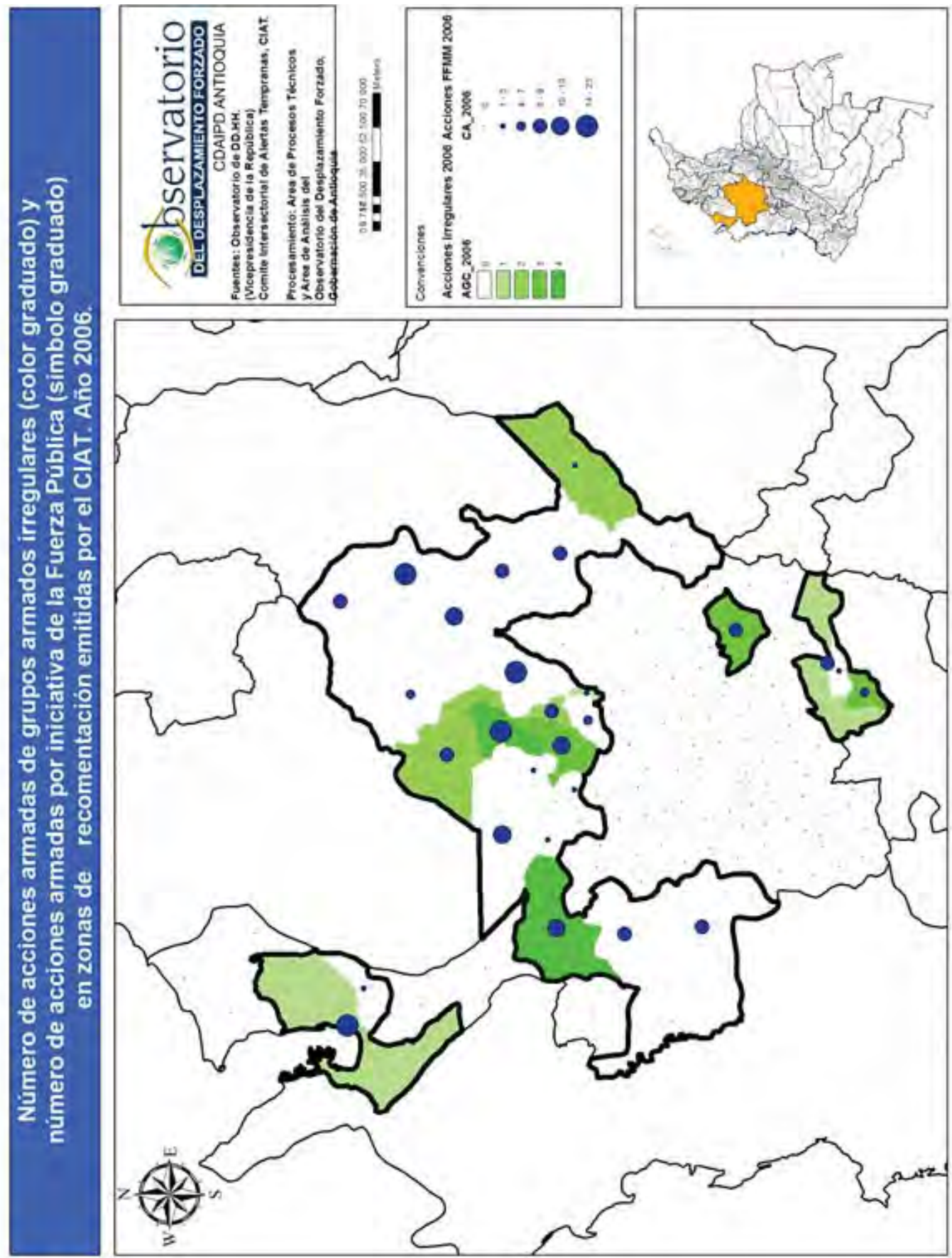

MAPA 20 Departamento de Antioquia. Número de acciones armadas de grupos al margen de la ley y por inciiativa de la fuerza pública en la Zona CIAT 2006. Fuente: Estadísticas del Observatorio de DD. HH. y DIH Vicepresidencia de la República. Procesado Oddif, julio 2010. 
Factores de Riesgo para el Desplazamiento, Protección de Tierras y Garantias de no Repetición en Zonas Vulnerables de Antioquia.
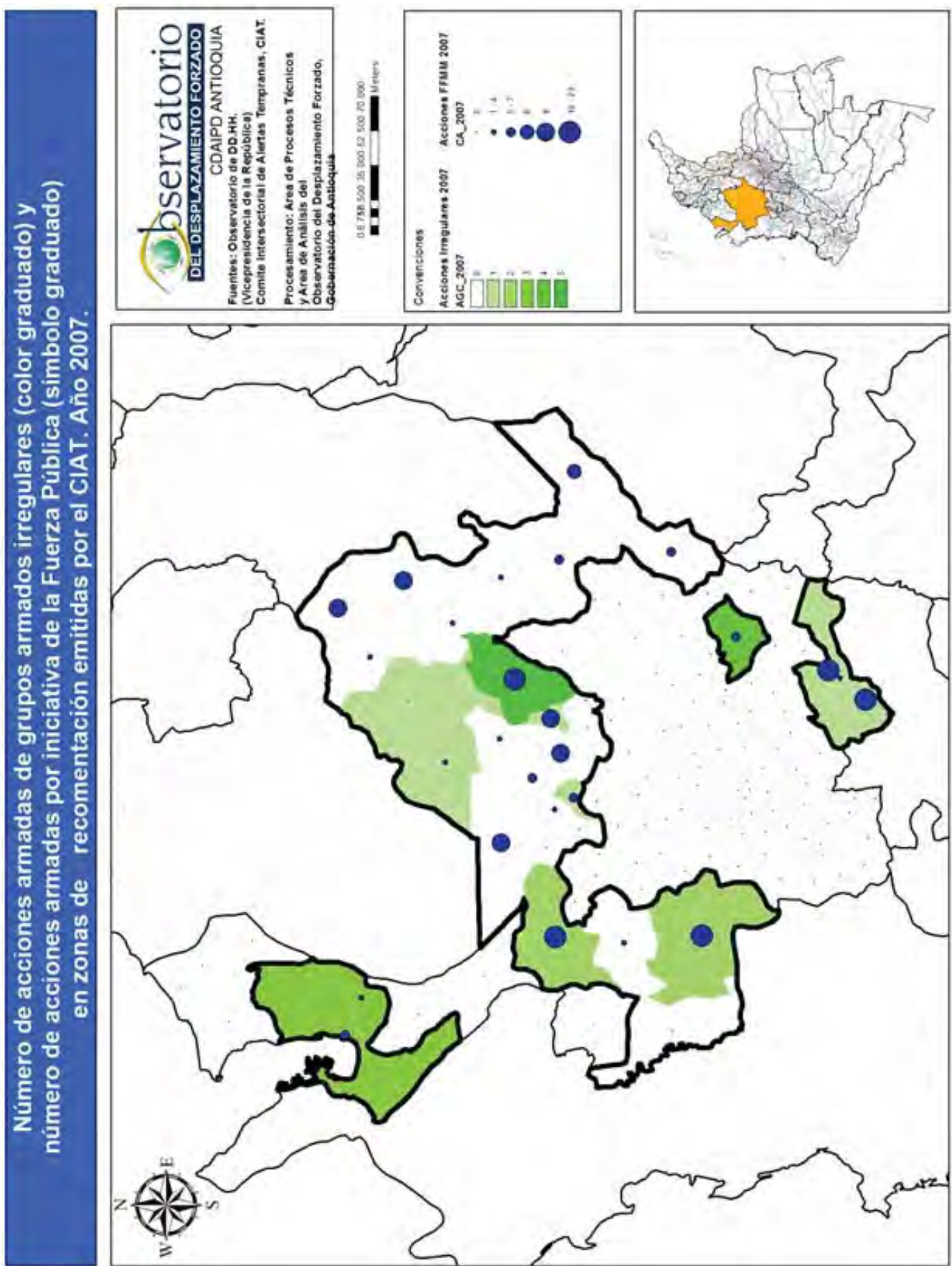

MAPA 21: Departamento de Antioquia. Número de acciones armadas de grupos al margen de la ley y por inciiativa de la fuerza pública en la Zona CIAT 2007. Fuente: Estadísticas del Observatorio de DD. HH. y DIH Vicepresidencia de la República. Procesado Oddif, julio 2010. 
Factores de Riesgo para el Desplazamiento, Protección de Tierras y Garantias de no Repetición en Zonas Vulnerables de Antioquia.
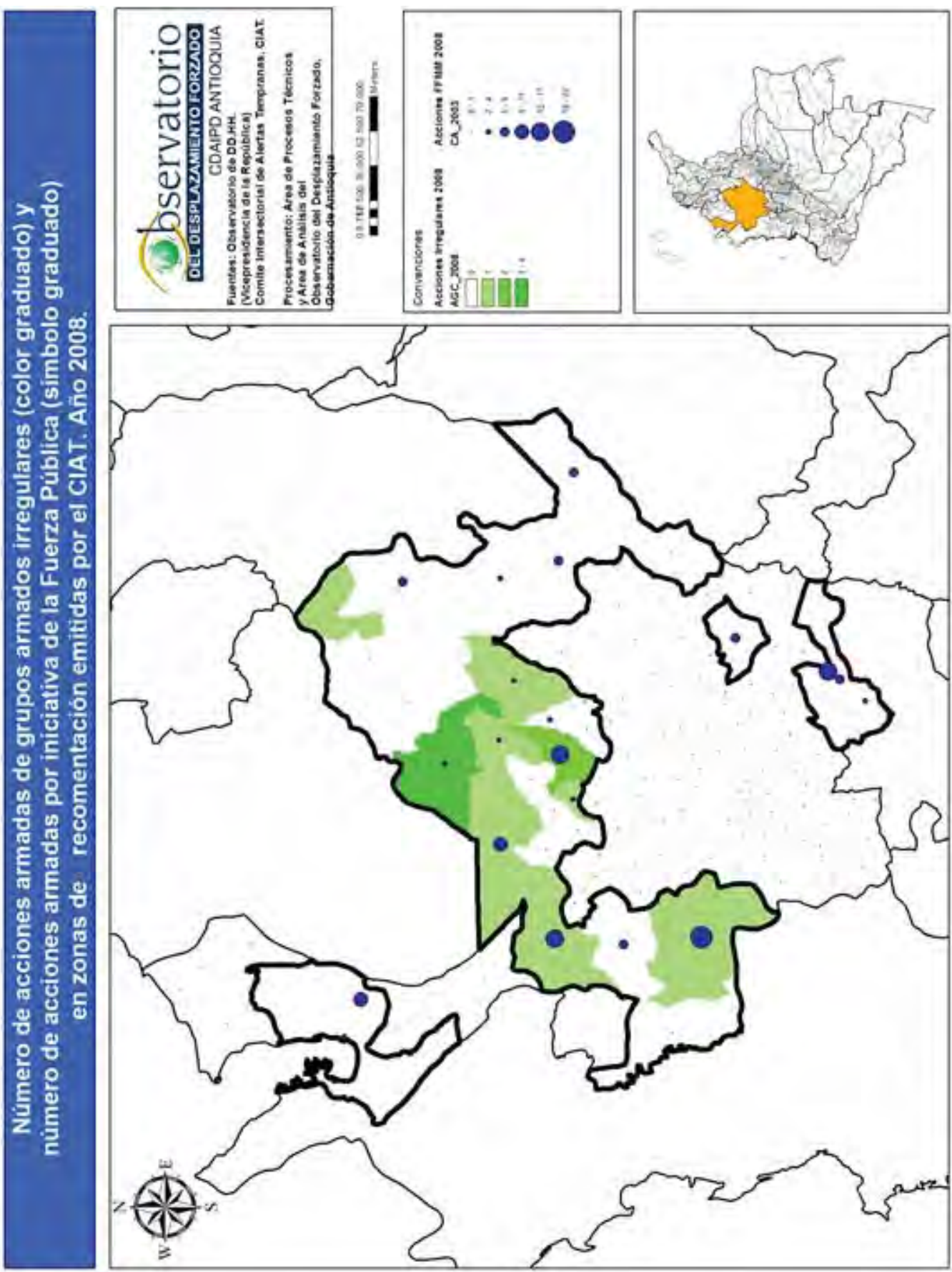

MAPA 22: Departamento de Antioquia. Número de acciones armadas de grupos al margen de la ley y por inciiativa de la fuerza pública en la Zona CIAT 2008. Fuente: Estadísticas del Observatorio de DD. HH. y DIH Vicepresidencia de la República. Procesado Oddif, julio 2010. 
Factores de Riesgo para el Desplazamiento, Protección de Tierras y Garantias de no Repetición en Zonas Vulnerables de Antioquia.
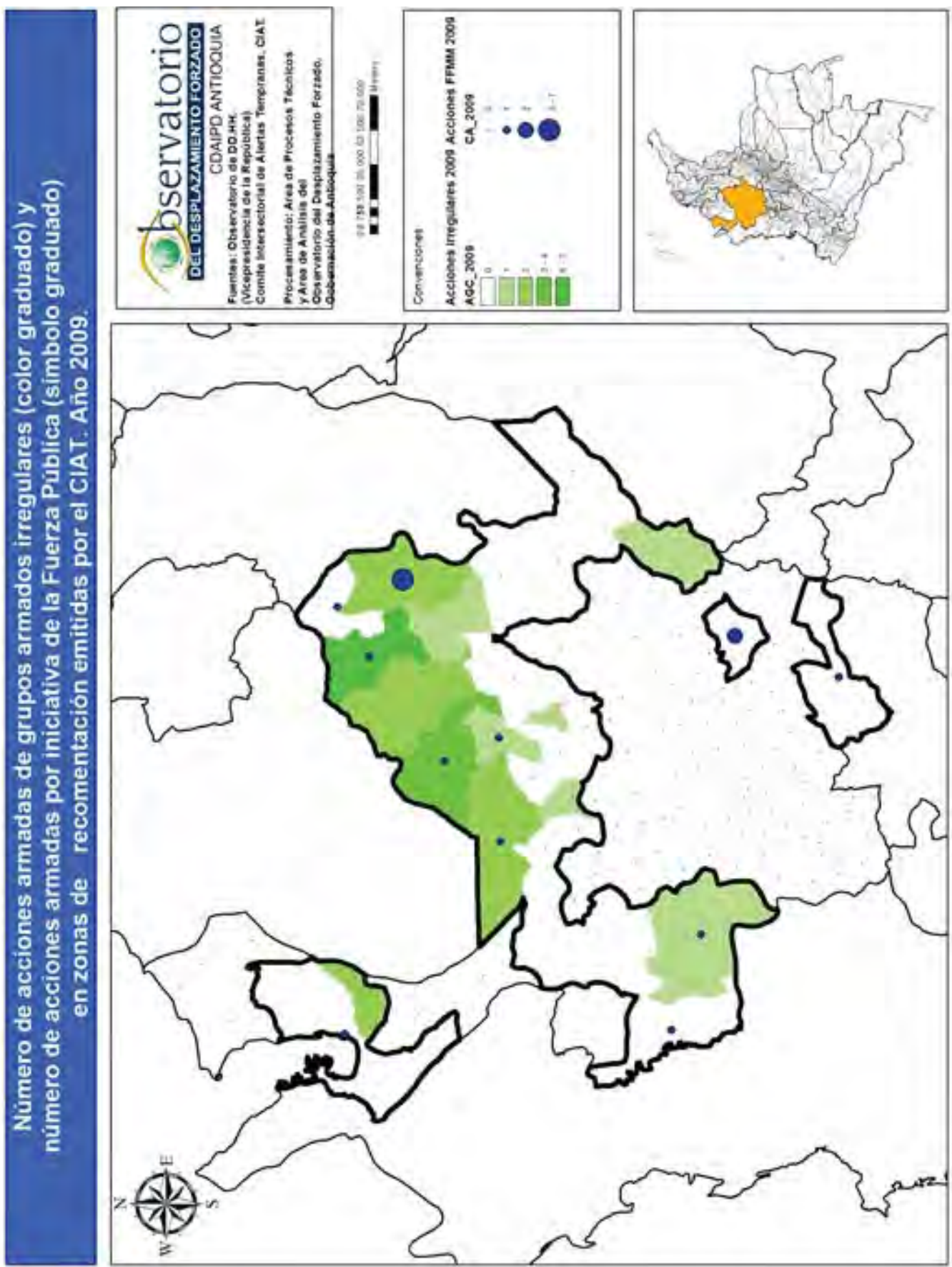

MAPA 23: Departamento de Antioquia. Número de acciones armadas de grupos al margen de la ley y por inciiativa de la fuerza pública en la Zona CIAT 2009. Fuente: Estadísticas del Observatorio de DD. HH. y DIH Vicepresidencia de la República. Procesado Oddif, julio 2010. 


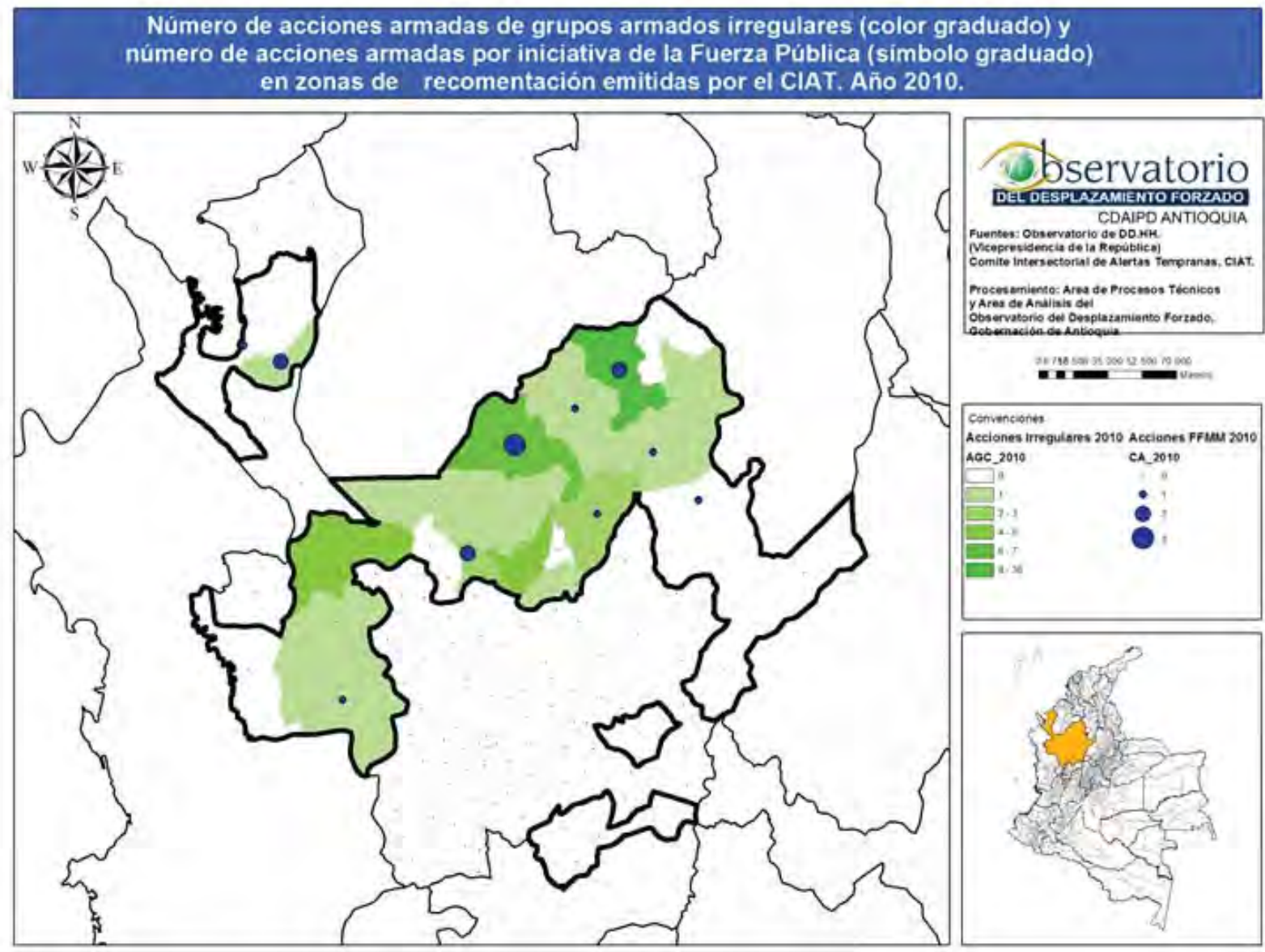

MAPA 24: Departamento de Antioquia. Número de acciones armadas de grupos al margen de la ley y por inciiativa de la fuerza pública en la Zona CIAT 2010. Fuente: Estadísticas del Observatorio de DD. HH. y DIH Vicepresidencia de la República. Procesado Oddif, julio 2010.

El registro de acciones armadas da cuenta de una paulatina concentración de acciones, legales e ilegales, en los municipios del Norte del departamento. El hecho de que para 2010 no haya registro de acciones en algunos municipios objeto de Alertas o Informes de Riesgo Electoral permite plantear, por ende, que la naturaleza de las amenazas sobre la población escapa al registro estadístico. Sin embargo, los mapas permiten llamar la atención sobre la desproporción entre la intensidad de acciones de grupos armados ilegales y legales, lo que facilita pensar en áreas en donde la iniciativa bélica corresponde, de manera diferenciada, a las fuerzas estatales, a las fuerzas insurgentes o a los grupos criminales.

Víctimas mensuales de Minas Anti Persona (MAP) en zonas con recomendaciones emitidas por el CIAT. 
En la zona de estudio el comportamiento de los eventos por MAP es el observado en la siguiente gráfica. En ella es posible apreciar que los picos corresponden a los años 2003, 2006 y 2009.

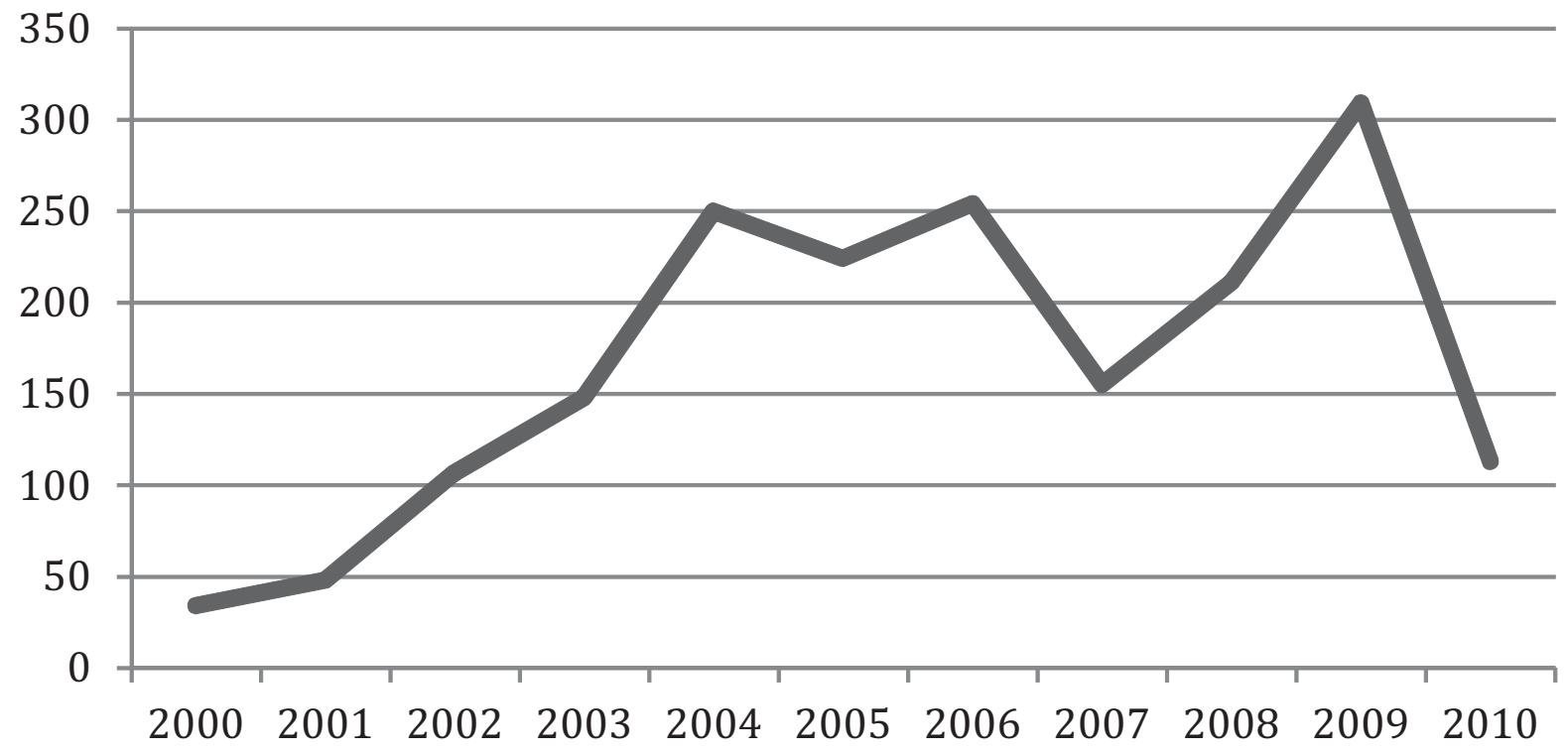

Figura 03: Departamento de Antioquia. Número de víctimas MAP en municipios con informe de riesgo SAT, años 2000 a 2010. Fuente: Estadísticas del Observatorio de DD. HH. y DIH Vicepresidencia de la República. Procesado Oddif, julio 2010 .

A continuación se presenta el número de accidentes por minas antipersonal y munición sin explotar considerando las variables diferenciales sexo y edad; aunque el indicador no precisa esta información, el Observatorio realiza este cálculo con el fin de complementar las estadísticas generales sobre población víctima del desplazamiento en Antioquia. De esta manera se orienta cualificadamente el diseño de programas y políticas de protección y prevención desde el enfoque diferencial.

La siguiente distribución permite observar el impacto diferenciado sobre la población y profundizar en el análisis sobre el riesgo que corren los hombres adultos, los cuales presentan la mayor afectación. Esta situación podría explicarse por el tipo de labores que realizan en el área rural de los municipios con presencia de estos artefactos proscritos por el DIH. 


\begin{tabular}{|lrrrrrr}
$\begin{array}{l}\text { Clasificación } \\
\text { indicador }\end{array}$ & $\begin{array}{r}\text { Mujeres } \\
\text { mayores de 18 }\end{array}$ & $\begin{array}{r}\text { Hombres } \\
\text { mayores de } \mathbf{1 8}\end{array}$ & $\begin{array}{r}\text { Niñas entre 0 } \\
\mathbf{y} \mathbf{1 7}\end{array}$ & $\begin{array}{r}\text { Niños entre 0 } \\
\text { y 17 }\end{array}$ & Total \\
\hline $\begin{array}{l}\text { Personas heridas por } \\
\text { MAP }\end{array}$ & 19 & 165 & 4 & 8 & 196 \\
$\begin{array}{l}\text { Personas } \\
\text { MUSE }\end{array}$ & 2 & 7 & 0 & 0 & 9 \\
Total & 21 & 172 & 4 & 8 & 205
\end{tabular}

Tabla 03. Departamento de Antioquia. Número de personas desplazadas afectadas por minas antipersonal y munición sin explotar, según sexo y edad. Periodo 1991-2010. Fuente: Sipod, diciembre 2010. Proyecto de acción contra minas, departamento de Antioquia, junio 2010. Procesamiento Oddif, julio 2011.

Aunque no hace parte de la medición de atentados a la integridad, en la base de datos se registra un total de 18 personas víctimas de desplazamiento, fallecidas a causa de accidentes por minas y munición sin explotar. Los siguientes mapas dan cuenta de los accidentes e incidentes de MAP y MUSE en Antioquia durante la última década. Aquí se destaca la presencia de este tipo de victimización en las áreas sobre las que han recaído informes CIAT.

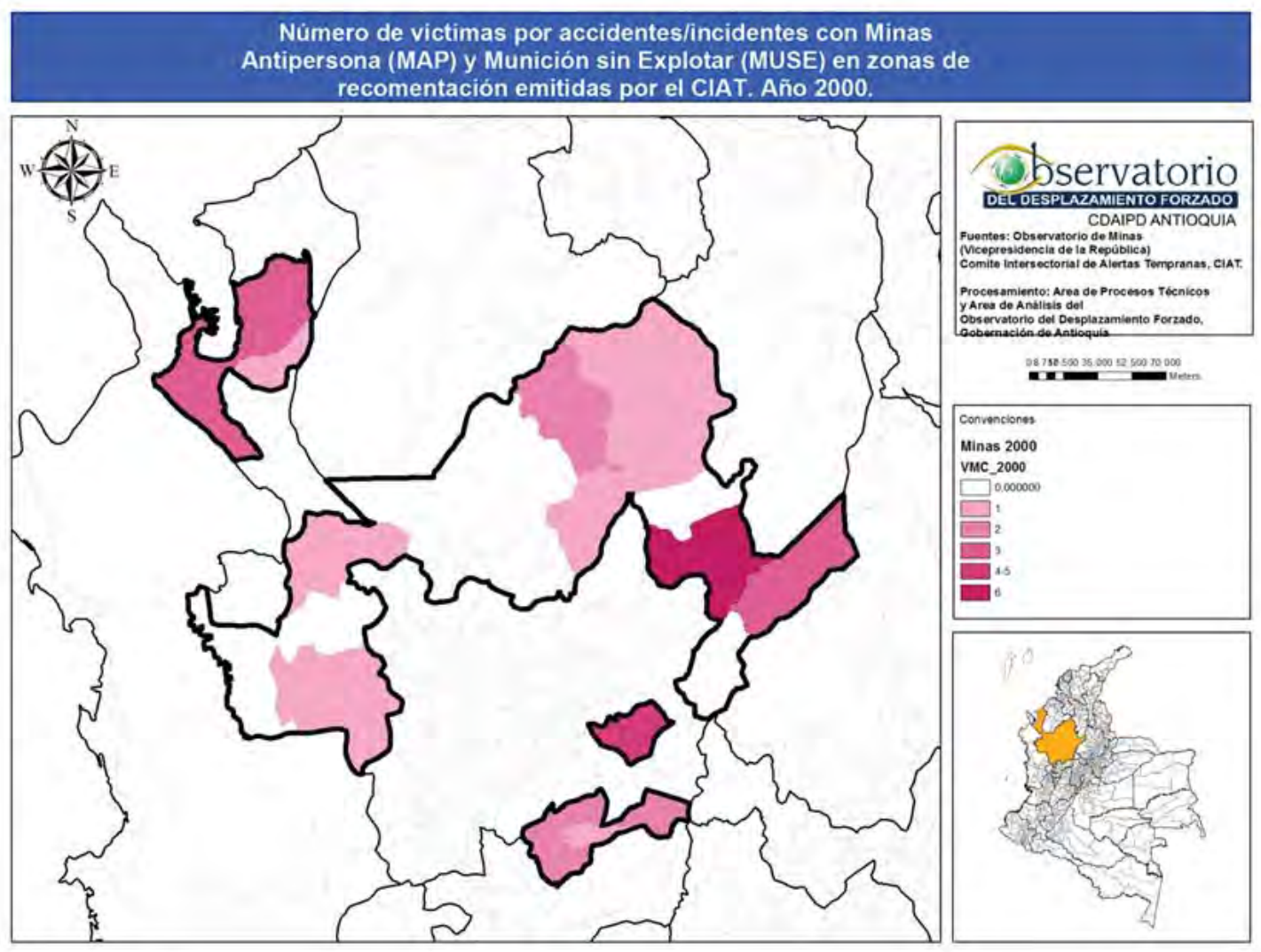

MAPA 25: Departamento de Antioquia. Número de víctimas por accidentes/incidentes con MAP y MUSE en la Zona CIAT 2000. Fuente: Estadísticas del Observatorio de DD. HH. y DIH Vicepresidencia de la República. Procesado Oddif, julio 2010 
Factores de Riesgo para el Desplazamiento, Protección de Tierras y Garantias de no Repetición en Zonas Vulnerables de Antioquia.

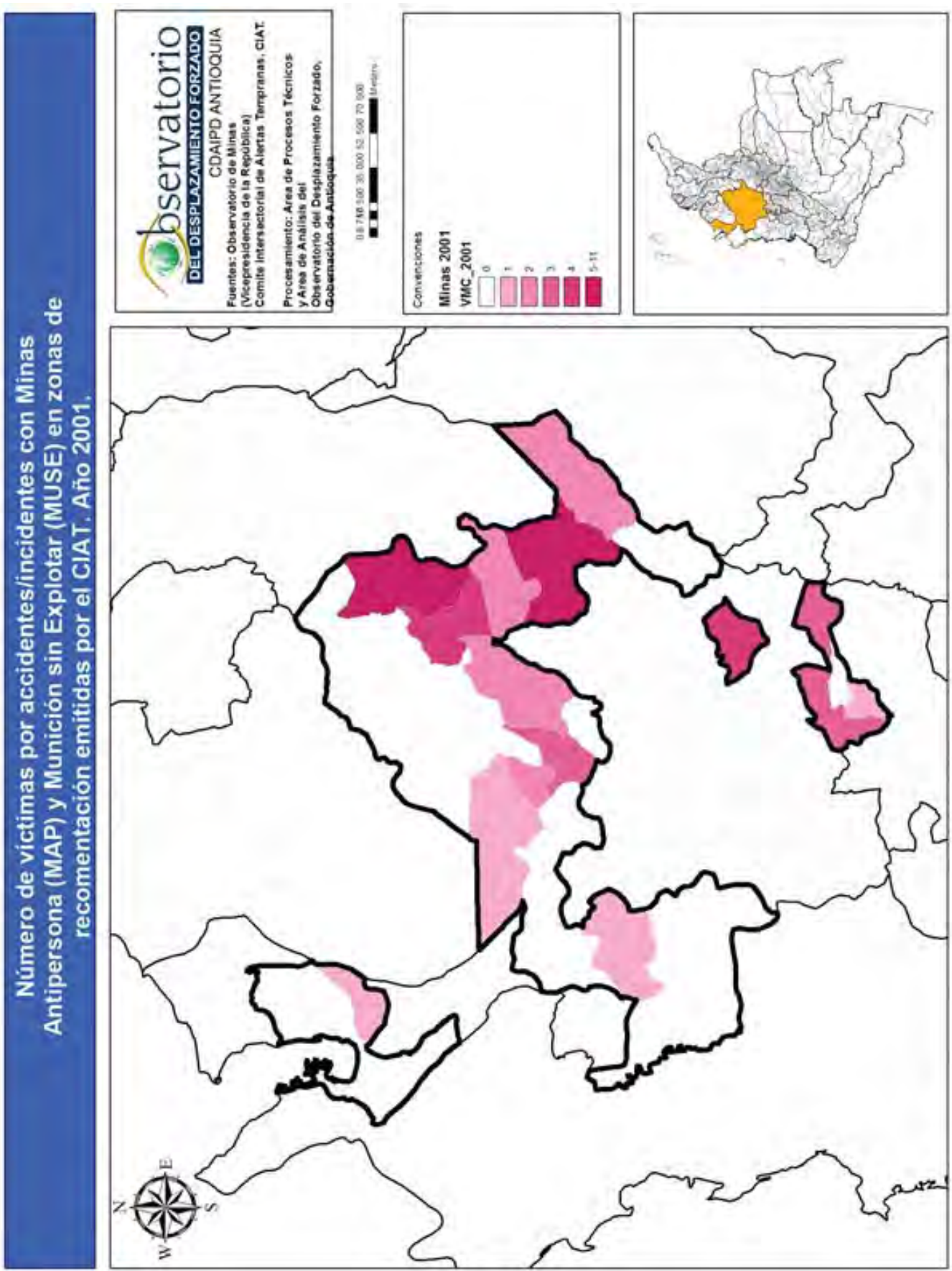

MAPA 26: Departamento de Antioquia. Número de víctimas por accidentes/incidentes con MAP y MUSE en la Zona CIAT 2001. Fuente: Estadísticas del Observatorio de DD. HH. y DIH Vicepresidencia de la República. Procesado Oddif, julio 2010. 
Factores de Riesgo para el Desplazamiento, Protección de Tierras y Garantias de no Repetición en Zonas Vulnerables de Antioquia.

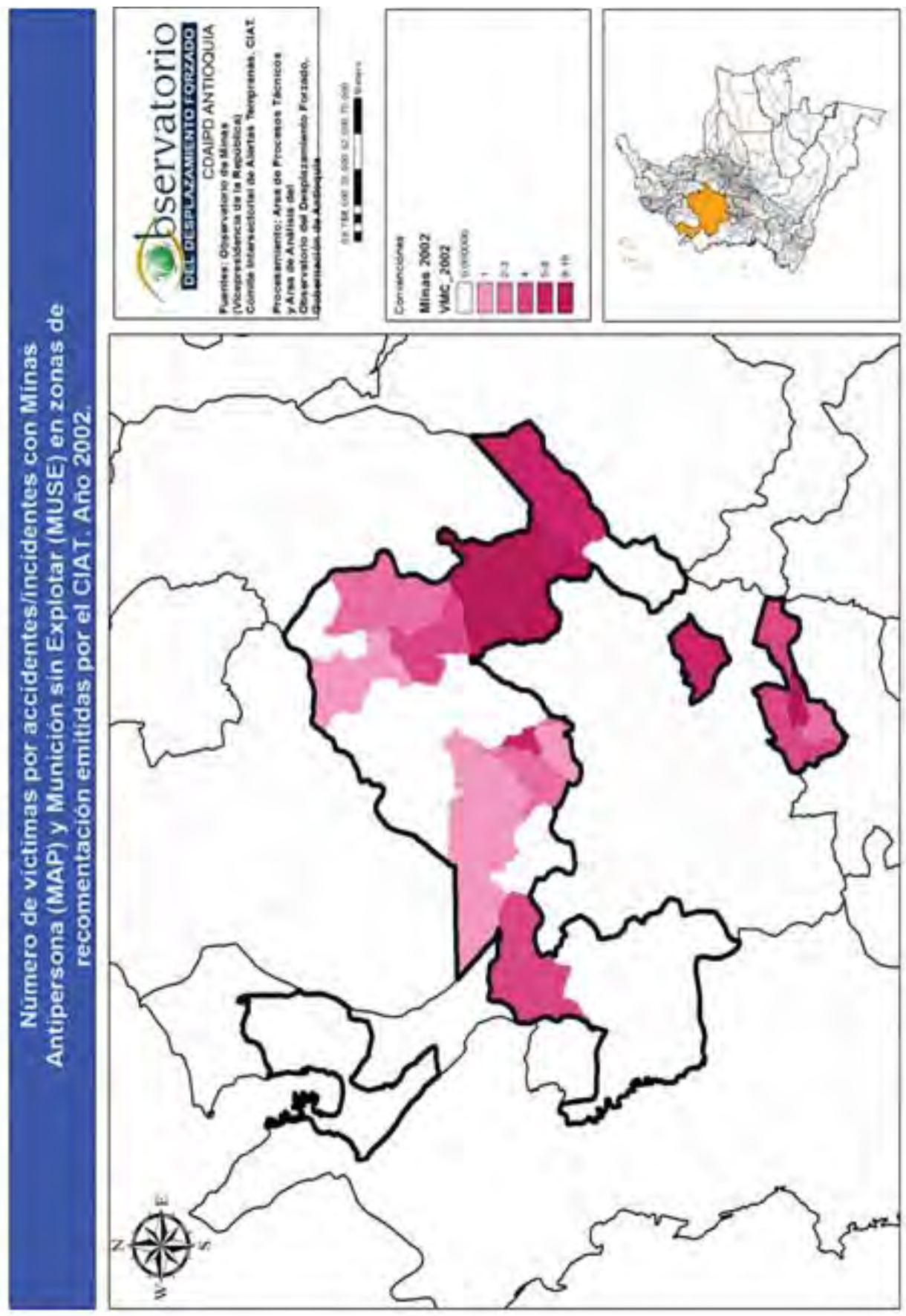

MAPA 27: Departamento de Antioquia. Número de víctimas por accidentes/incidentes con MAP y MUSE en la Zona CIAT 2002. Fuente: Estadísticas del Observatorio de DD. HH. y DIH Vicepresidencia de la República. Procesado Oddif, julio 2010 . 
Factores de Riesgo para el Desplazamiento, Protección de Tierras y Garantias de no Repetición en Zonas Vulnerables de Antioquia.

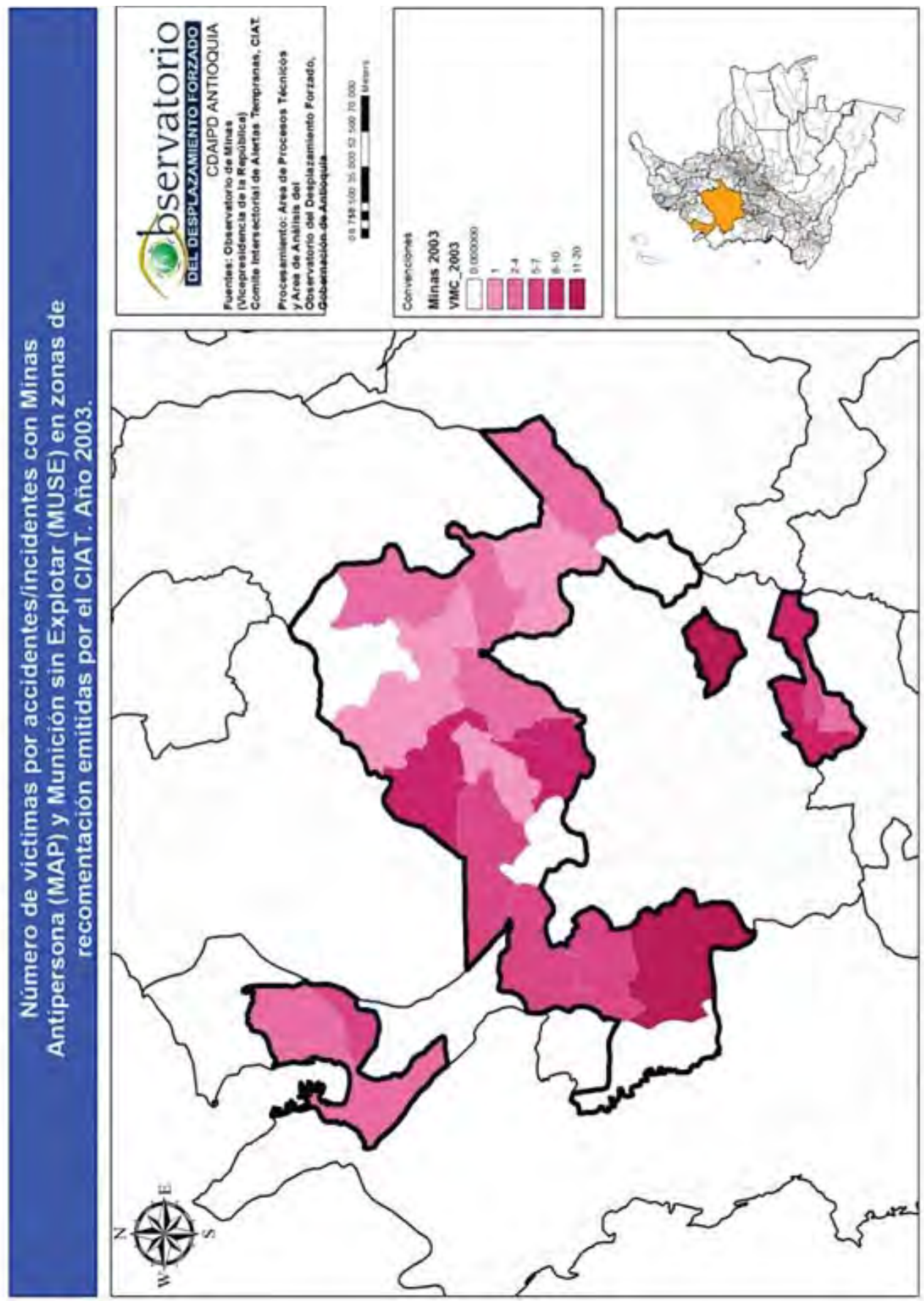

MAPA 28: Departamento de Antioquia. Número de víctimas por accidentes/incidentes con MAP y MUSE en la Zona CIAT 2003. Fuente: Estadísticas del Observatorio de DD. HH. y DIH Vicepresidencia de la República. Procesado Oddif, julio 2010 . 
Factores de Riesgo para el Desplazamiento, Protección de Tierras y Garantias de no Repetición en Zonas Vulnerables de Antioquia.

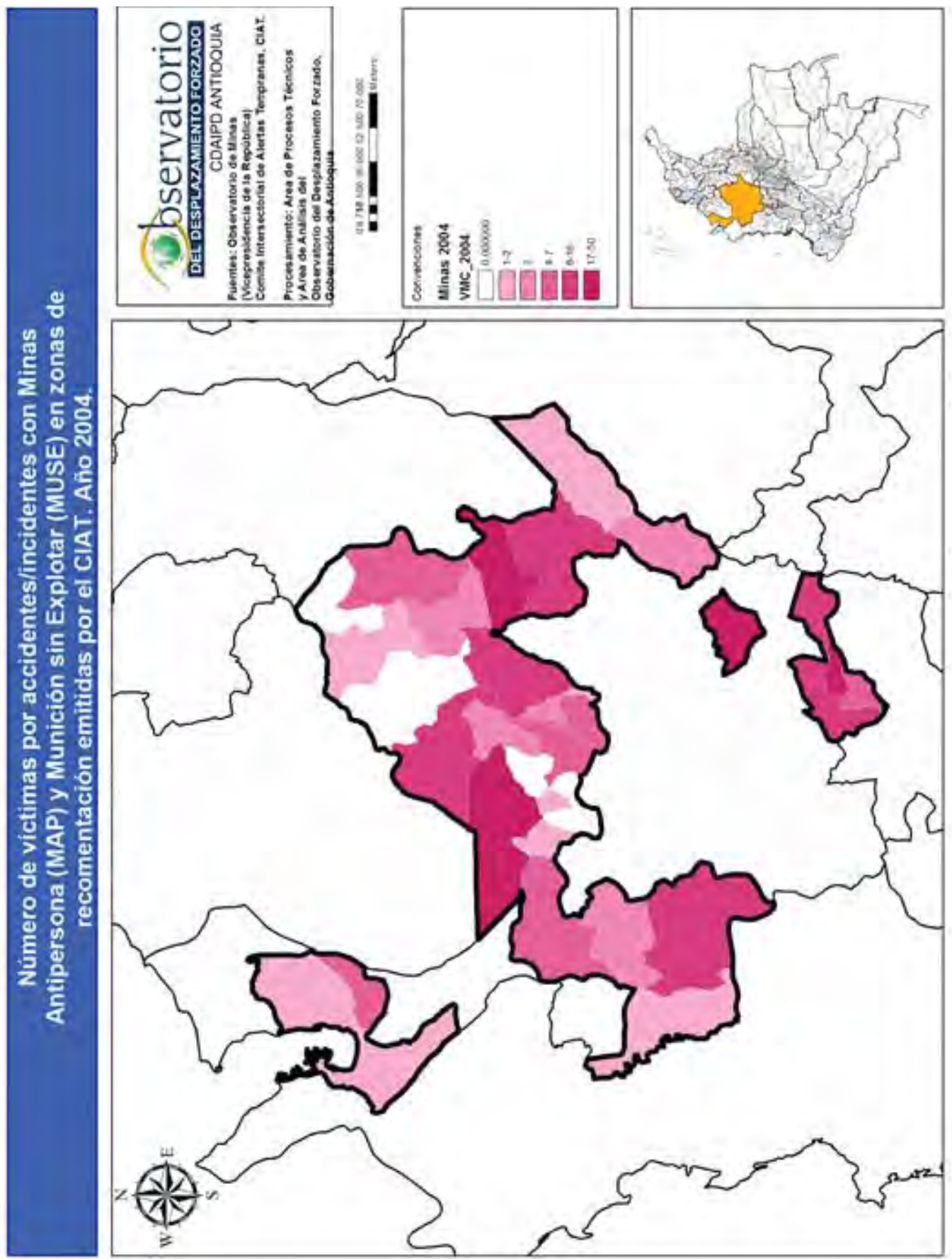

MAPA 29: Departamento de Antioquia. Número de víctimas por accidentes/incidentes con MAP y MUSE en la Zona CIAT 2004. Fuente: Estadísticas del Observatorio de DD. HH. y DIH Vicepresidencia de la República. Procesado Oddif, julio 2010.

5270 AGo.USB Medellín-Colombia V. $12 \quad N^{\circ} 2 \quad$ PP. 214- 547 Julio-Diciembre 2012 ISSN: 1657-8031 
Factores de Riesgo para el Desplazamiento, Protección de Tierras y Garantias de no Repetición en Zonas Vulnerables de Antioquia.

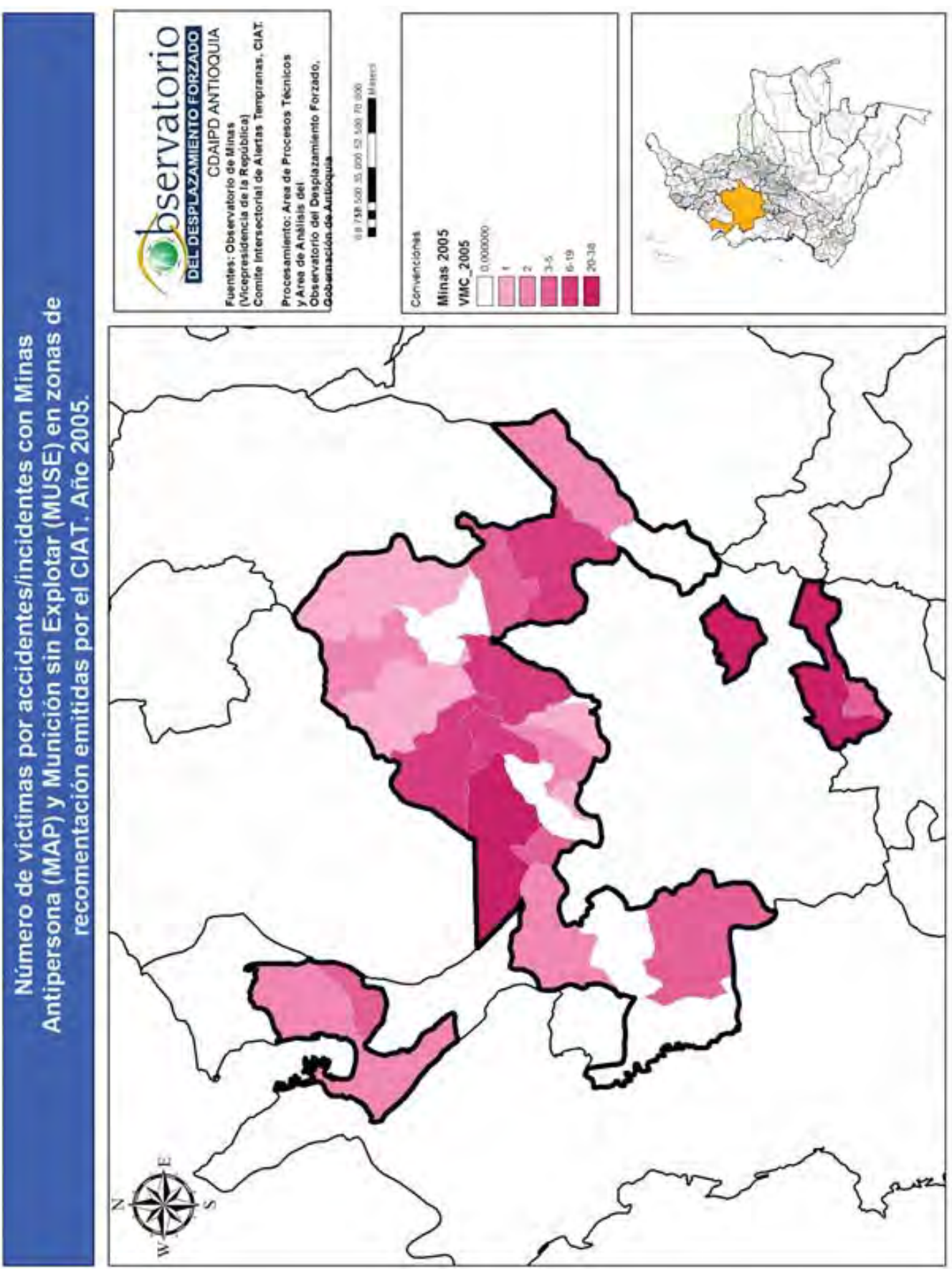

MAPA 30: Departamento de Antioquia. Número de víctimas por accidentes/incidentes con MAP y MUSE en la Zona CIAT 2005. Fuente: Estadísticas del Observatorio de DD. HH. y DIH Vicepresidencia de la República. Procesado Oddif, julio 2010. 
Factores de Riesgo para el Desplazamiento, Protección de Tierras y Garantias de no Repetición en Zonas Vulnerables de Antioquia.

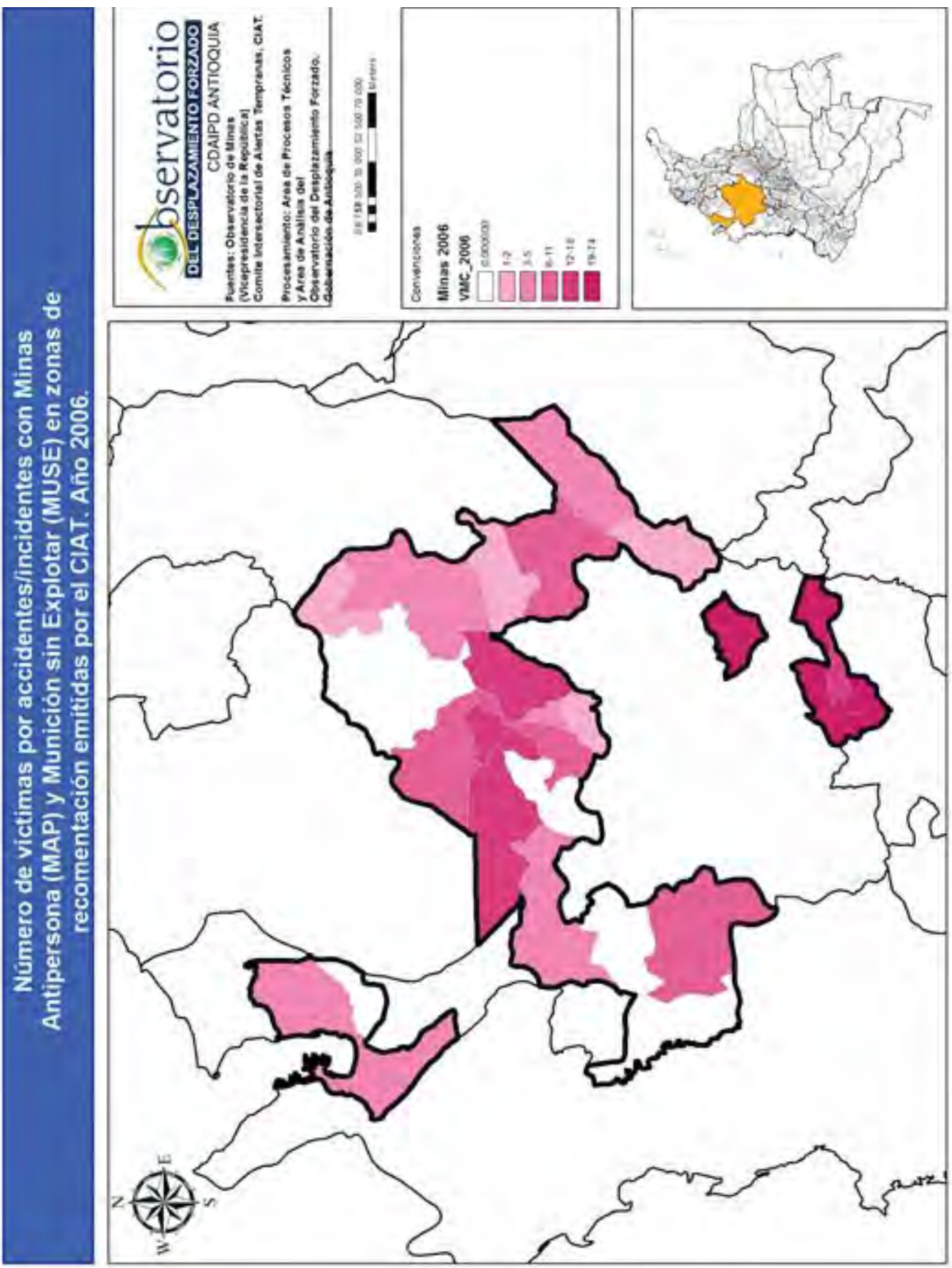

MAPA 31: Departamento de Antioquia. Número de víctimas por accidentes/incidentes con MAP y MUSE en la Zona CIAT 2006. Fuente: Estadísticas del Observatorio de DD. HH. y DIH Vicepresidencia de la República. Procesado Oddif, julio 2010.

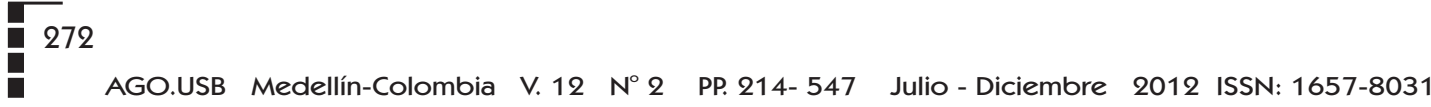


Factores de Riesgo para el Desplazamiento, Protección de Tierras y Garantias de no Repetición en Zonas Vulnerables de Antioquia.

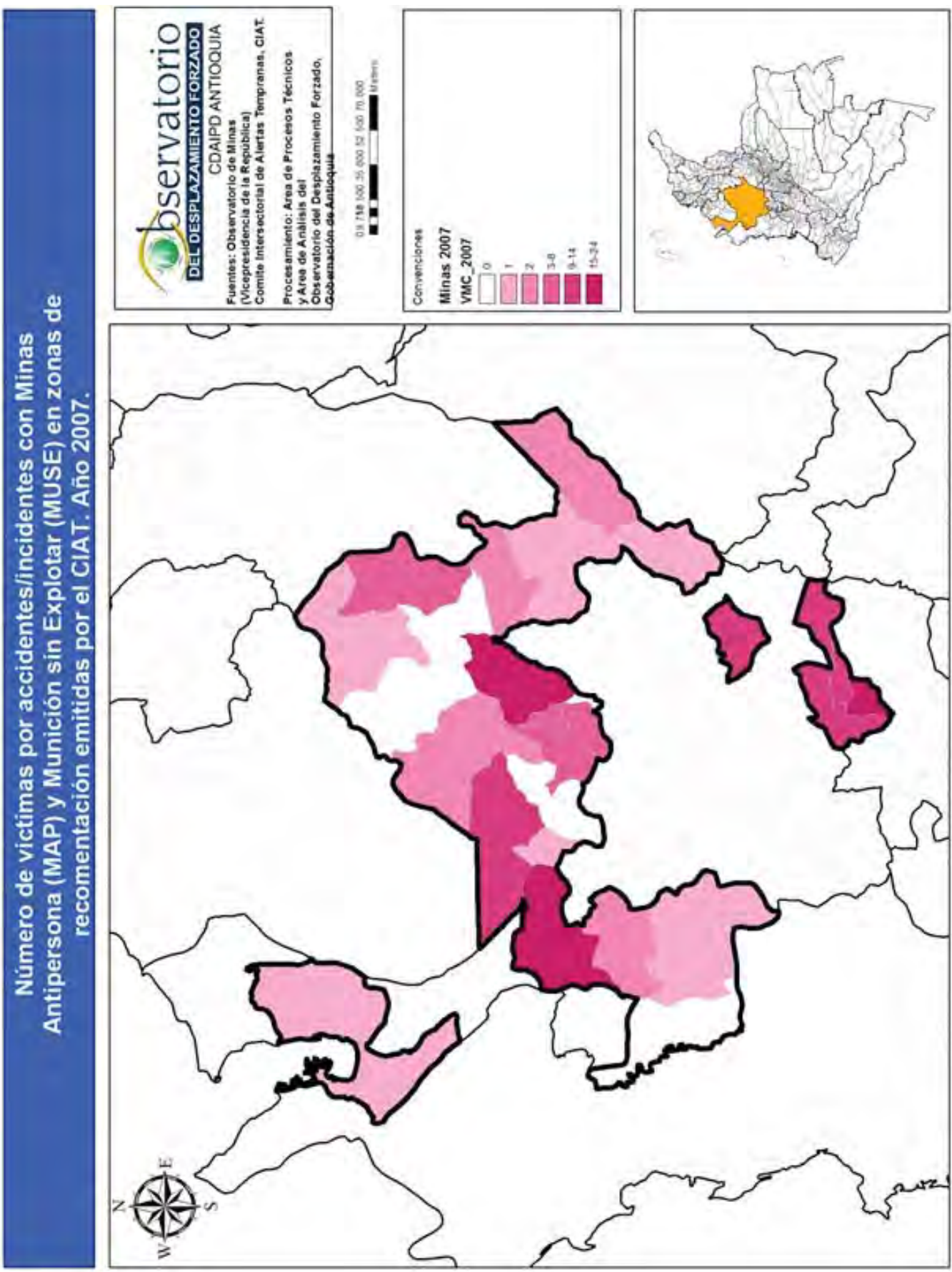

MAPA 32: Departamento de Antioquia. Número de víctimas por accidentes/incidentes con MAP y MUSE en la Zona CIAT 2007. Fuente: Estadísticas del Observatorio de DD. HH. y DIH Vicepresidencia de la República. Procesado Oddif, julio 2010. 


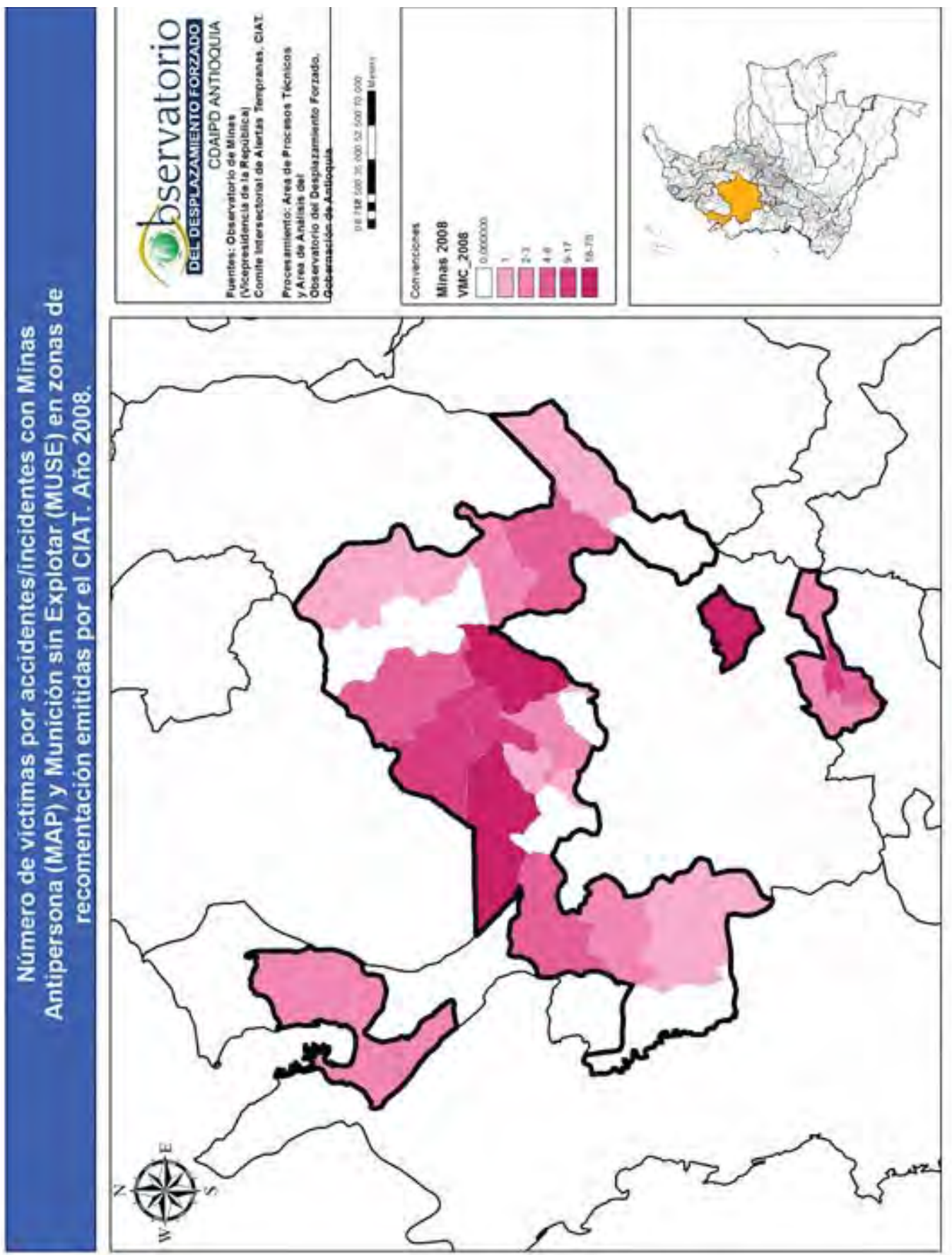

MAPA 33: Departamento de Antioquia. Número de víctimas por accidentes/incidentes con MAP y MUSE en la Zona CIAT 2008. Fuente: Estadísticas del Observatorio de DD. HH. y DIH Vicepresidencia de la República. Procesado Oddif, julio 2010 
Factores de Riesgo para el Desplazamiento, Protección de Tierras y Garantias de no Repetición en Zonas Vulnerables de Antioquia.

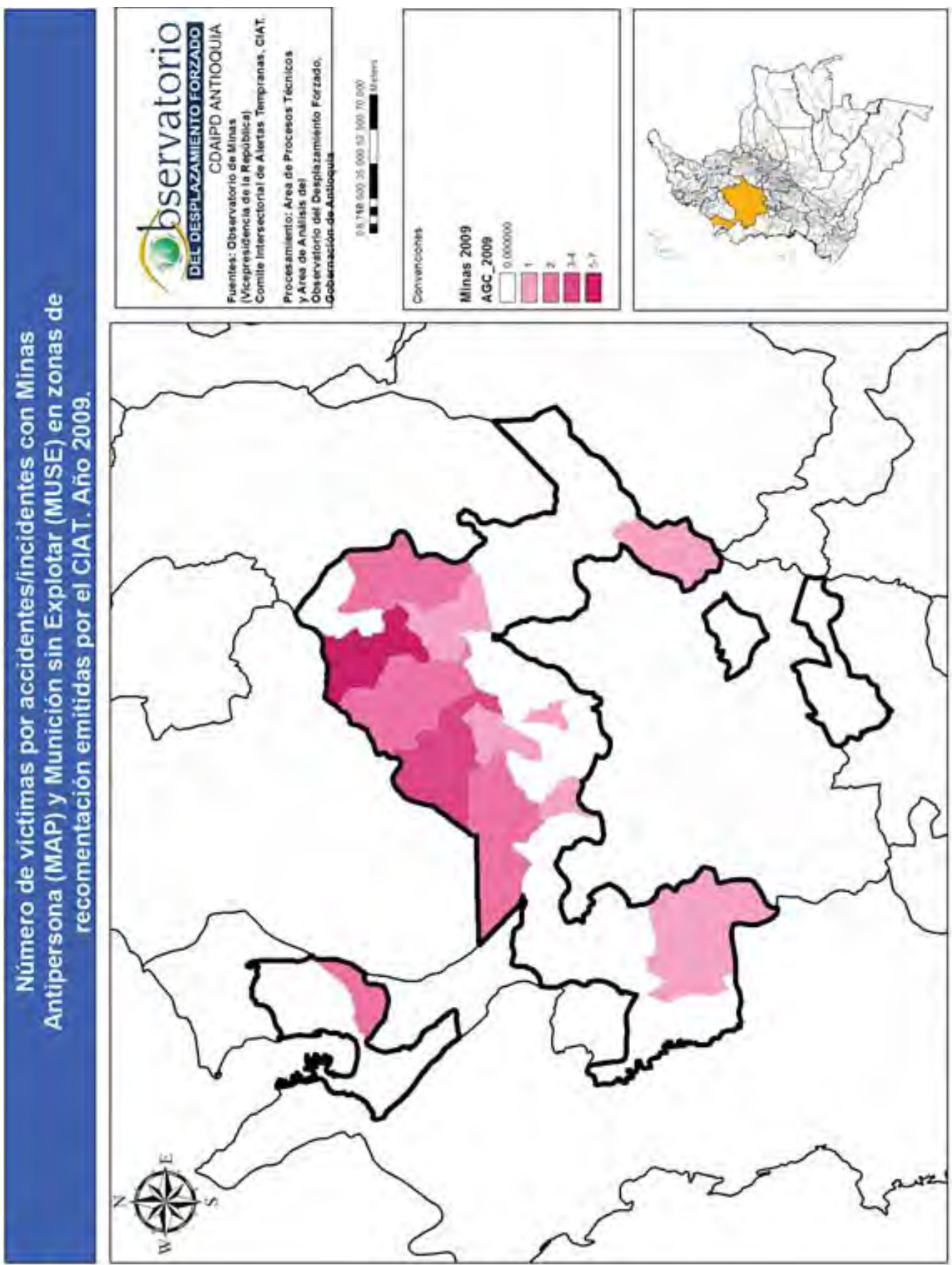

MAPA 34: Departamento de Antioquia. Número de víctimas por accidentes/incidentes con MAP y MUSE en la Zona CIAT 2009. Fuente: Estadísticas del Observatorio de DD. HH. y DIH Vicepresidencia de la República. Procesado Oddif, julio 2010. 
Factores de Riesgo para el Desplazamiento, Protección de Tierras y Garantias de no Repetición en Zonas Vulnerables de Antioquia.

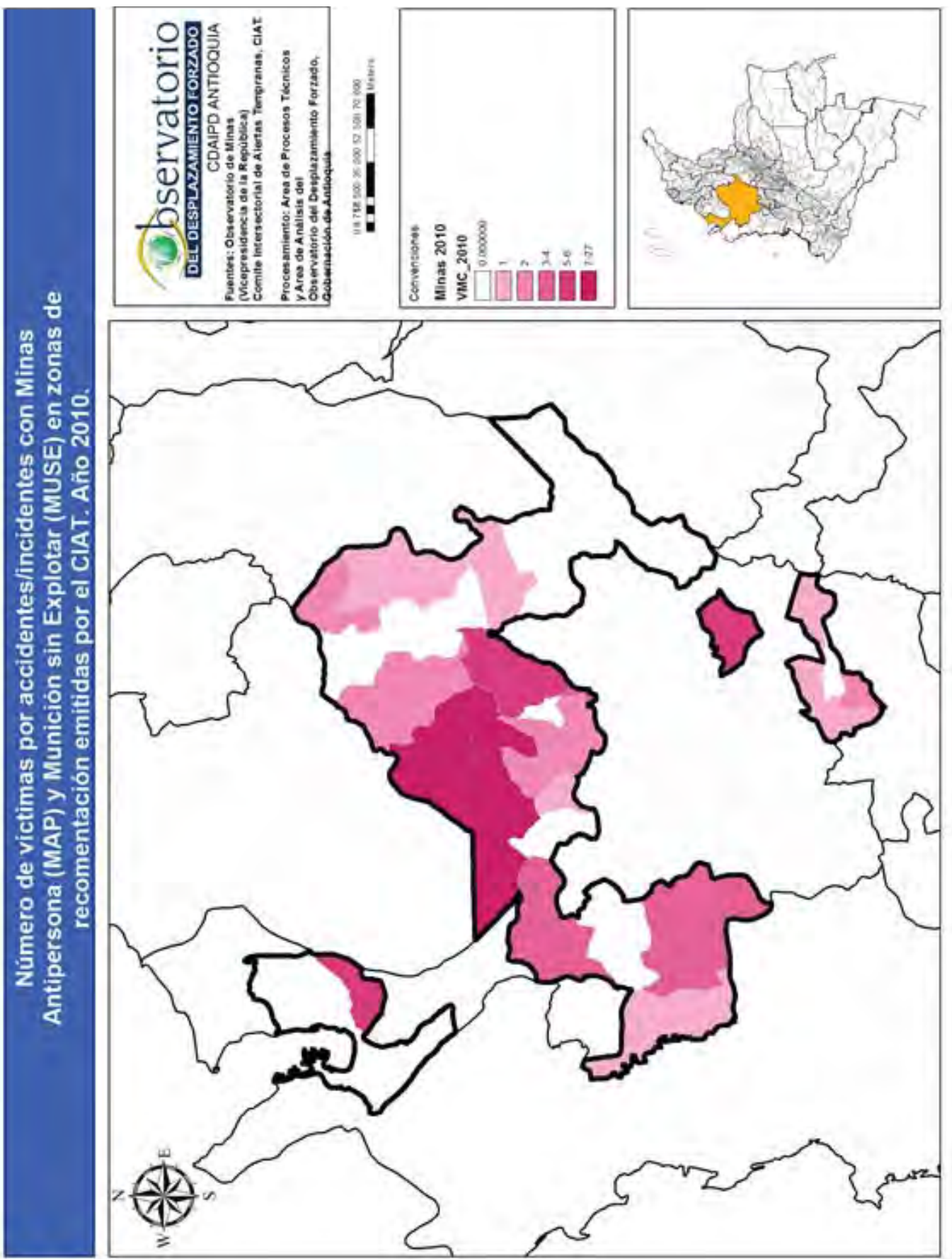

MAPA 35: Departamento de Antioquia. Número de víctimas por accidentes/incidentes con MAP y MUSE en la Zona CIAT 2010. Fuente: Estadísticas del Observatorio de DD. HH. y DIH Vicepresidencia de la República. Procesado Oddif, julio 2010.

5276 AGo.USB Medellín-Colombia V. $12 \quad N^{\circ} 2 \quad$ PP. 214- 547 Julio-Diciembre 2012 ISSN: 1657-8031 
Si bien es dificil establecer patrones espaciales a partir de los datos, se percibe una intensificación del fenómeno conforme avanza la serie, del año 2000 al 2010. Al finalizar dicha serie incidentes y accidentes de MAP y MUSE tienden a concentrarse en el municipio de Ituango y aledaños, una zona que al inicio de la década no fue afectada por la presencia de estos artefactos. Lo mismo puede plantearse para el Bajo Cauca. Se destaca que las afectaciones por minas tienden a incrementarse en algunas zonas sin que desaparezcan en otras; por tanto no se trata de un fenómeno gradual cuya dinámica sea cíclica.

La dimensión de indicadores como los antes tratados puede dar lugar a que las autoridades departamentales y municipales adelanten planes de contingencia para evitar posibles desplazamientos forzados. Uno de los indicadores medidos calcula la relación entre municipios con planes de contingencia y los municipios identificados en riesgo.

Para este ejercicio se tomaron los municipios con informe de riesgo emitido por el CIAT, como de los municipios que cuentan con un plan de contingencia validado ante los comités locales de atención integral a la población desplazada (CLAIPD).

\begin{tabular}{cccc}
$\begin{array}{c}\text { Municipios con planes } \\
\text { de contingencia }\end{array}$ & $\begin{array}{c}\text { Municipios identificados } \\
\text { en riesgo }\end{array}$ & $\begin{array}{c}\text { Total de informes de } \\
\text { riesgo 2004-2011 }\end{array}$ & $\begin{array}{c}\text { Municipios con planes } \\
\text { de contingencia / } \\
\text { Municipios }\end{array}$ \\
\hline 10 & 20 & 29 & $\begin{array}{c}\text { identificados en riesgo } \\
\text { ides }\end{array}$
\end{tabular}

Tabla 04. Porcentaje de municipios con planes de contingencia frente al total de municipios identificados en riesgo. 2004-2011. Fuente: Comité Interinstitucional de Alertas Tempranas - CIAT. Comités locales de atención integral a la población desplazada. Procesamiento Oddif julio 2011. 


\begin{tabular}{|c|c|c|}
\hline Municipio & $\begin{array}{l}\text { Número de } \\
\text { informes } \\
\text { de riesgo }\end{array}$ & $\begin{array}{r}\text { Plan de } \\
\text { contingencia }\end{array}$ \\
\hline Anorí & 1 & Sí \\
\hline Apartadó & 4 & No \\
\hline Argelia & 1 & No \\
\hline Briceño & 1 & Sí \\
\hline Cáceres & 1 & Sí \\
\hline Caucasia & 1 & Sí \\
\hline Dabeiba & 1 & No \\
\hline El Bagre & 1 & Sí \\
\hline Ituango & 1 & Sí \\
\hline Medellín & 4 & No \\
\hline Nechí & 2 & Sí \\
\hline Remedios & 1 & No \\
\hline San Carlos & 1 & No \\
\hline Sonsón & 1 & No \\
\hline Tarazá & 1 & Sí \\
\hline Turbo & 2 & No \\
\hline Valdivia & 1 & Sí \\
\hline $\begin{array}{l}\text { Vigía del } \\
\text { Fuerte }\end{array}$ & 2 & No \\
\hline Yarumal & 1 & No \\
\hline Zaragoza & 1 & Sí \\
\hline $\begin{array}{l}\text { Total } \\
\text { Informes }\end{array}$ & 29 & \\
\hline
\end{tabular}

Tabla 05: Departamento de Antioquia. Número de informes de riesgo por municipio y adopción de Plan de Contingencia, periodo 2004-2011. Fuente: Comité Interinstitucional de Alertas Tempranas - CIAT. Comités locales de atención integral a la población desplazada. Procesado Oddif julio 2011. 
El siguiente mapa destaca los municipios declarados con informe de riesgo y los que han contado con planes de contingencia.

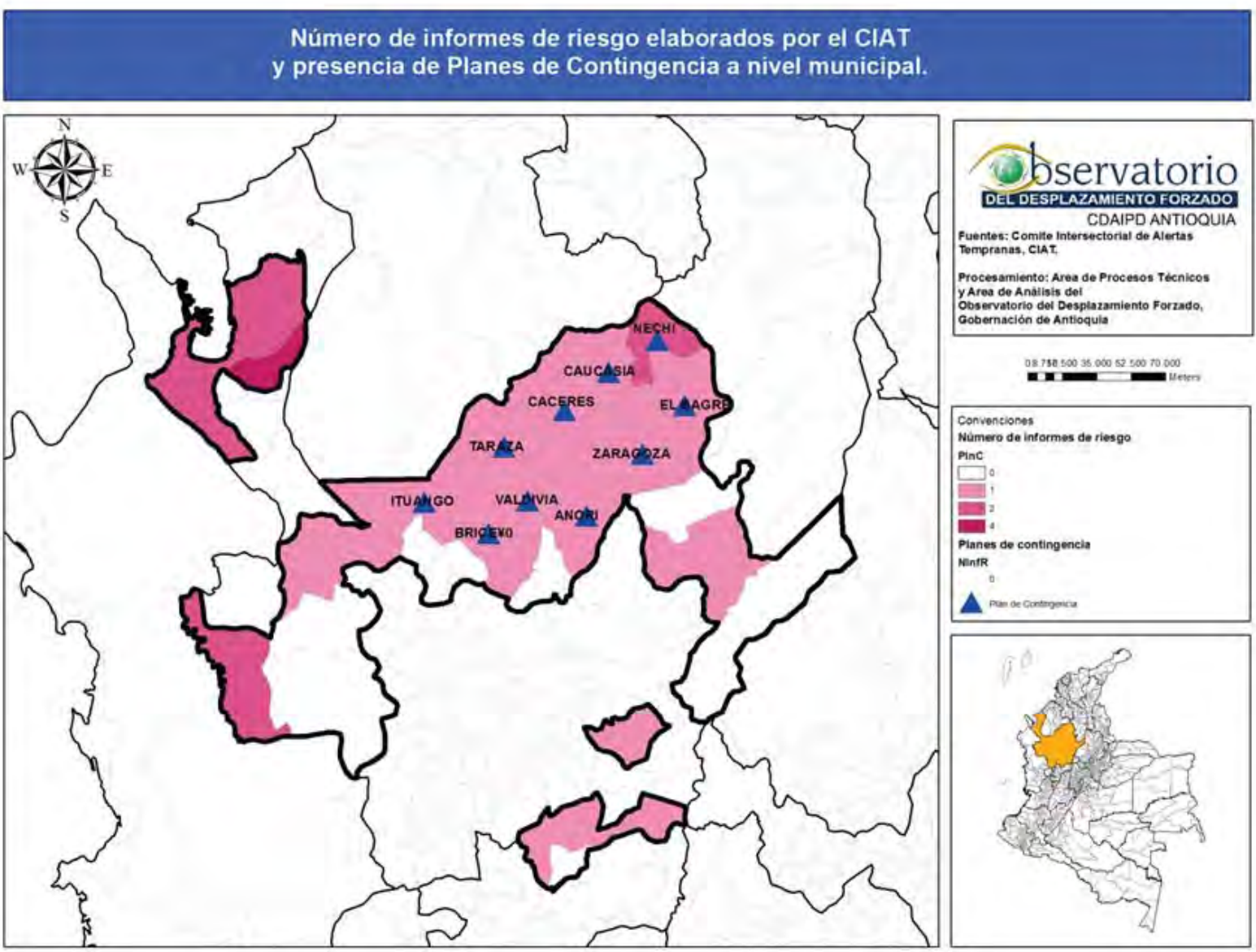

MAPA 36: Departamento de Antioquia. Número de informes de riesgo elaborados por el CIAT y presencia de planes de contingencia a nivel municipal en la Zona CIAT 2007. Fuente: CIAT. Procesado Oddif, julio 2010.

Dentro de la zona CIAT se destaca que la presencia de informes de riesgo no implicó, necesariamente, la elaboración de un plan de contingencia. Estos planes se concentraron de manera específica en municipios de la zona norte de Antioquia; zona que como se observó en los mapas anteriores da cuenta de una creciente intensidad de la violencia homicida y armada.

Tras el registro de estos indicadores, la siguiente sección del artículo dará cuenta del impacto de las dinámicas de violencia en la tenencia de la tierra.

Tercera Parte: tierras y desplazamiento forzado.

Uno de los impactos de mayor trascendencia que ha estado aparejado al desplazamiento forzado lo es el despojo de tierras. Una de las vías de protección con la que cuentan las 
personas víctimas de este fenómeno, o que se encuentran en riesgo de tal afectación, lo suponen las solicitudes de protección de derechos sobre predios y territorios abandonados a causa del desplazamiento forzado.

La medición de este indicador implicó la utilización de la base de datos del Registro Único de Predios y Territorios abandonados -Rupta-, la cual contiene información sobre solicitudes de protección en este tópico, en el territorio nacional. Esta base de datos fue cruzada con la información del Sipod, con el fin de identificar a las personas allí incluidas y que han solicitado protección de los predios.

El cálculo se realizó a partir de las solicitudes de protección sobre predios ubicados en el departamento de Antioquia, filtrando los datos para el 'departamento de ubicación' = Antioquia, con el fin de obtener el total de las tramitadas. Posteriormente se realizó el filtro de acuerdo con la variable 'Estado Rupta' para identificar las solicitudes que han sido aprobadas. Los resultados se muestran en la siguiente tabla:

\begin{tabular}{cccc}
$\begin{array}{c}\text { Solicitudes de } \\
\text { protección recibidas en } \\
\text { Antioquia }\end{array}$ & $\begin{array}{c}\text { Solicitudes de protección } \\
\text { aprobadas en el sistema } \\
\text { RUP en Antioquia }\end{array}$ & $\begin{array}{c}\text { Solicitudes de } \\
\text { protección de predios } \\
\text { de personas con } \\
\text { registro en Sipod } \\
\text { aprobadas }\end{array}$ & $\begin{array}{c}\text { Porcentaje de } \\
\text { solicitudes individuales } \\
\text { de protección } \\
\text { aprobadas }\end{array}$ \\
\hline 7102 & 1848 & 1037 & $26,02 \%$
\end{tabular}

Tabla 06. Departamento de Antioquia. Porcentaje de solicitudes de protección sobre predios y territorios abandonados a causa del desplazamiento, aprobadas en el sistema RUP. Fuente: Registro único de predios y territorios abandonados (Rupta) - Instituto colombiano para el desarrollo rural (Incoder).

El siguiente mapa destaca los municipios en donde se han registrado informes para la protección de predios, expedidos por el Comité local de atención integral a la población desplazada, CLAIPD, de los municipios en donde se ha dado una declaratoria de desplazamiento inminente. El mapa relaciona la proporción porcentual de cada territorio municipal con el total de hectáreas declaradas para su protección. 


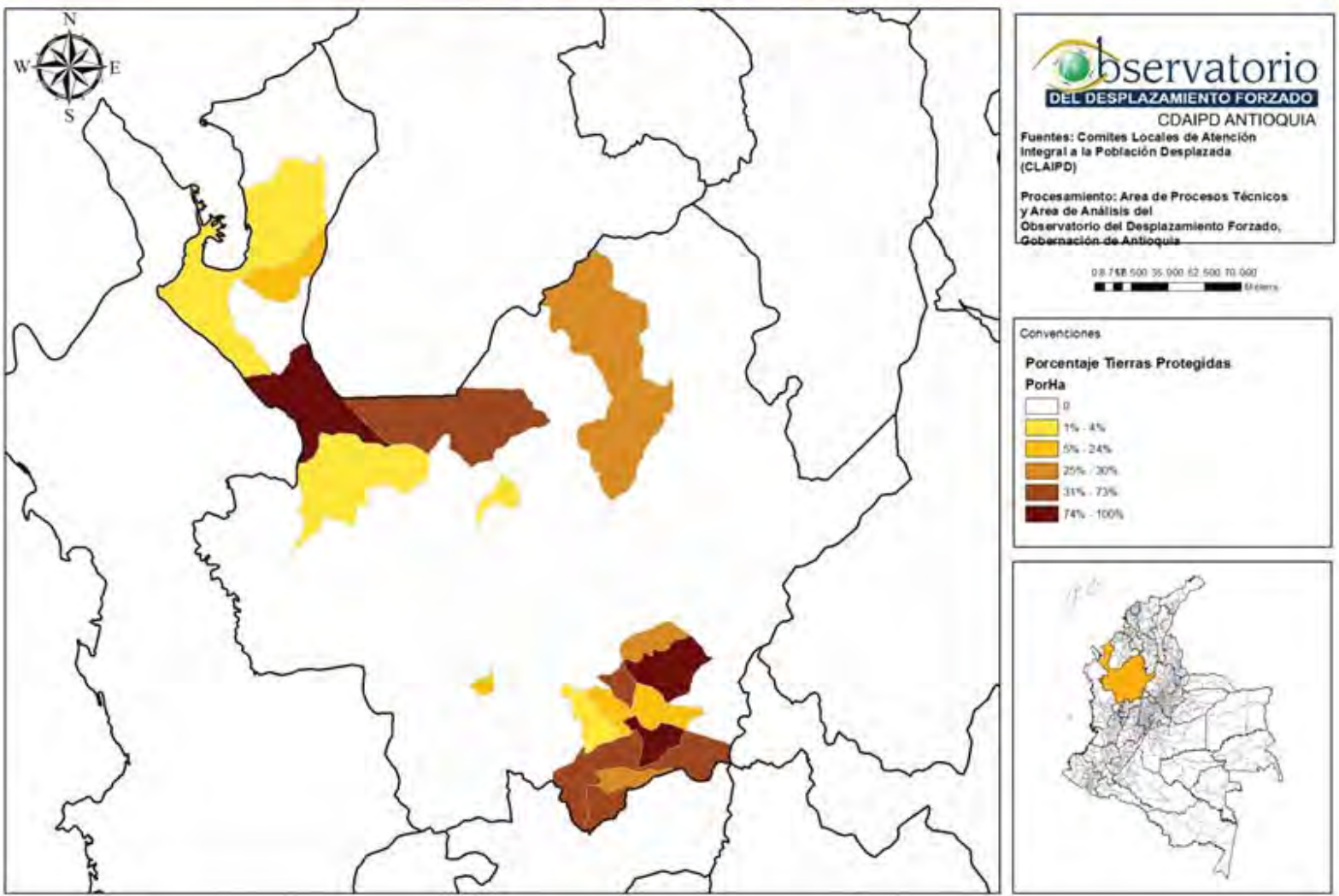

MAPA 37: Departamento de Antioquia. Municipios con declaratoria de riesgo inminente y la proporción de hectáreas declaradas para su protección. Datos acumulados a 2010. Fuente: RUPTA. Procesado Oddif, julio 2010.

La distribución de los municipios permite establecer que el Oriente antiqueño, Urabá y los de la zona Norte concentran este tipo de medidas. Según los rangos de la información, tres municipios (San Carlos, San Francisco y Mutatá) han protegido entre el 74\% y 100\% del total de su área municipal, ante la inminencia de desplazamientos. Información de este tipo permite establecer hipótesis en torno a los destinos privilegiados de presión criminal sobre la tierra en Antioquia.

La medición del indicador "Declaratorias con informes de predios expedidos por los Comités territoriales de atención integral a la población desplazada (CTAIPD) / Declaratorias de desplazamiento o de inminencia expedidas por los CTAIPD" se realizó a partir de los datos sobre informes de predios tramitados en los comités locales de atención integral a población desplazada, contrastados con el total de informes de desplazamiento o de inminencia emitidos por dichos comités territoriales. La información se presenta en las siguientes tablas. 
Las cifras analizadas, y la cartografia realizada, dan cuenta que una de las orientaciones predominantes de la violencia armada en el departamento se orienta hacia la tenencia de la tierra. La relación porcentual entre las hectáreas de un municipio y el total de estas que se han declarado como protegidas da cuenta que las protecciones han sido solicitadas para extensiones significativas en cada municipio.

La siguiente y última sección del artículo establecerá, a manera de conclusión, el alcance de las garantías de no repetición a partir de la medición de indicadores relativos a la cobertura de la justicia en torno a la población en situación de desplazamiento.

\section{Conclusiones.}

Balance de las garantías de no repetición.

Uno de los indicadores medidos para el informe GED comprendió las "Investigaciones iniciadas por el delito de desplazamiento / Denuncias por el delito de desplazamiento".

Respecto a este indicador, el Observatorio del Depslazamiento encontró que la información relacionada con el denominador del mismo, 'Denuncias por el delito de desplazamiento', según la base de datos suministrada por la Unidad de Justicia y Paz de la Fiscalía General de la Nación, con corte a 13 de septiembre de 2010, no contiene la variable relacionada con el número de investigaciones iniciadas respecto a este delito.

Dicho indicador, por tanto, presenta el siguiente resultado: según la fiscalía son 4.045 denuncias por el delito de desplazamiento forzado en Antioquia; no existen registros de investigaciones adelantadas al respecto. Este indicador, en suma, puede dar cuenta de de las débiles garantías de no repetición en cuanto a que la justicia, como una parte importante de tales garantías, no se ha hecho efectiva a la hora de adelantar las investigaciones sobre el delito.

Cabe recordar, ante este panorama, el pronunciamiento que hiciera del director de la Oficina en Colombia del Alto Comisionado de las Naciones Unidas para los Derechos Humanos en 2004, sobre los derechos a la verdad, a la justicia y a la reparación integral en casos de graves violaciones a los derechos humanos, en referencia a la problemática de la impunidad en el caso de graves crímenes. El tema fue examinado por las Naciones Unidas según un estudio del Relator Especial, quien además presentó un proyecto de 'Conjunto de principios para la protección y promoción de los derechos humanos mediante la lucha contra la impunidad', aprobado por la Subcomisión para la Protección y Promoción de los Derechos Humanos, en 1997. Tal pronunciamiento, en referencia a las 'Garantías de no Repetición', señala:

"Entre la satisfacción y las garantías de no repetición se incluyen varias medidas que apuntan a una reparación simbólica y otras orientadas a la prevención de violaciones, construyendo las condiciones para evitar la repetición de las mismas. En síntesis, se plantea el deber del Estado de "adoptar medidas adecuadas para que las víctimas no puedan volver a ser objeto de violaciones que vulneren su dignidad”. 


$\begin{array}{ccc}\begin{array}{c}\text { Municipios con informes de } \\ \text { predios expedidos por el } \\ \text { Claipd }\end{array} & \begin{array}{c}\text { Municipios } \\ \text { con declaratorias de } \\ \text { desplazamiento o de } \\ \text { inminencia expedidas } \\ \text { por el Claipd }\end{array} & \begin{array}{c}\text { Porcentaje de } \\ \text { declaratorias con } \\ \text { informes de } \\ \text { predios expedidos } \\ \text { por el Claipd }\end{array} \\ 18 & 20 & 90 \%\end{array}$

Tabla 07. Departamento de Antioquia. Número de declaratorias de predios expedidos por los Claipd. Fuente: Comités territoriales de atención integral a la población desplazada. Procesamiento, Observatorio Departamental del Desplazamiento Interno Forzado por la Violencia - abril de 2010.

\begin{tabular}{lrrr} 
Municipio & $\begin{array}{r}\text { Área total por } \\
\text { municipio (ha) }\end{array}$ & $\begin{array}{r}\text { Área declarada por } \\
\text { municipio (ha) }\end{array}$ & $\begin{array}{r}\text { Informe } \\
\text { de } \\
\text { predios }\end{array}$ \\
\hline Angelópolis & 8700 & 1045 & $\mathrm{Si}$ \\
Anorí & 143000 & 42635 & $\mathrm{No}$ \\
Apartadó & 60000 & 10492 & $\mathrm{Si}$ \\
Argelia & 25400 & 7200 & $\mathrm{Si}$ \\
Cáceres & 197300 & 59787.39 & $\mathrm{Si}$ \\
El Carmen de Viboral & 44800 & 1968 & $\mathrm{Si}$ \\
Cocorná & 21000 & 1612 & $\mathrm{Si}$ \\
Dabeiba & 188300 & 4200 & $\mathrm{Si}$ \\
Granada & 18300 & 13325 & $\mathrm{Si}$ \\
Ituango & 237400 & 91170.5 & $\mathrm{Si}$ \\
Mutatá & 110600 & 110600 & $\mathrm{No}$ \\
Nariño & 31300 & 13057.1 & $\mathrm{Si}$ \\
San Andrés de Cuerquia & 17700 & 11.03 & $\mathrm{Si}$ \\
San Carlos & 70200 & 55000 & $\mathrm{Si}$ \\
San Francisco & 37200 & 33821 & $\mathrm{Si}$ \\
San Luis & 45300 & 10857 & $\mathrm{Si}$ \\
San Rafael & 36200 & 8950 & $\mathrm{Si}$ \\
Sonsón & 132300 & 61000 & $\mathrm{Si}$ \\
Turbo & 305500 & 3022.8 & $\mathrm{Si}$ \\
Urrao & 255600 & & $\mathrm{Si}$
\end{tabular}

Tabla 08. Departamento de Antioquia. Municipios con declaratoria de protección colectiva en el departamento de Antioquia. Fuente: Registro único de predios y territorios abandonados (Rupta) - Instituto colombiano para el desarrollo rural (Incoder). 
Entre ellas figuran:

- La cesación de las violaciones.

- La verificación de los hechos y la publicidad de la verdad.

- La declaración oficial o la decisión judicial de reparación de la dignidad, de la reputación y de otros derechos de las víctimas.

- La disculpa y el reconocimiento público de los hechos y de las responsabilidades.

- Las conmemoraciones y los homenajes a las víctimas.

- La enseñanza y la difusión de la verdad histórica.

La garantía de no repetición está identificada con la adopción de las medidas necesarias para evitar que las víctimas sean afectadas con la comisión de nuevos crímenes del mismo género. El Comité de Derechos Humanos considera que el deber de reparar el daño no se satisface solamente por medio del ofrecimiento de una cantidad de dinero a los familiares de las víctimas. En primer término debe ponerse fin al estado de incertidumbre e ignorancia en que estos se encuentran, es decir, otorgar el conocimiento completo y público de la verdad, entendido como el derecho a saber, que asiste a las víctimas y sus familias. Considera además que el desconocimiento del derecho a la verdad constituye una violación del Pacto Internacional de Derechos Civiles y Políticos.

El derecho a conocer la verdad sobre los hechos que dieron lugar a violaciones de los derechos humanos, sus circunstancias específicas y la identidad de las personas que participaron en ellos, también hace parte del derecho a la reparación, en su modalidad de satisfacción y garantías de no repetición. La Comisión Interamericana de Derechos Humanos ha manifestado que el derecho a la verdad "constituye una obligación que el Estado debe satisfacer respecto a los familiares de las víctimas y la sociedad en general", no solo como mecanismo de reparación a las víctimas, sino también como forma de prevenir futuras violaciones.

En la Sentencia T-821 de 2007 la Corte Constitucional conceptuó que, el derecho a la reparación integral supone el derecho a la restitución de los bienes de los cuales la persona ha sido despojada; la indemnización de los perjuicios; y la rehabilitación del daño, así como medidas destinadas a la reivindicación de la memoria y de la dignidad de las víctimas. Adicionalmente, el Estado tiene la obligación de adoptar medidas de no repetición para garantizar que las organizaciones que perpetraron los crimenes investigados sean desmontadas y las estructuras que permitieron su comisión removidas, a fin de asegurar que tales crimenes no volverán a tener lugar.

Más adelante, en la misma sentencia, se afirma que:

Ahora bien, en cuanto a las medidas orientadas a la restitución; indemnización, rehabilitación del daño, y las garantías de no repetición de los crimenes, la propia Corte Interamericana de Derechos Humanos ha indicado que el derecho a la reparación "se rige, como ha sido aceptado universalmente, por el derecho internacional en todos sus aspectos: alcance, naturaleza, modalidades y la determinación de los beneficiarios, nada de lo cual puede ser modificado por el Estado obligado, invocando para ello disposiciones de su derecho interno". 
Los indicadores de goce efectivo, complementarios y asociados, de los derechos a la restitución, indemnización, rehabilitación, medidas de satisfacción, garantías de no repetición, a la igualdad y no discriminación, no cuentan con un modelo de estandarización de información. Aparecen informes fragmentarios como resultado de la implementación de proyectos puntuales, pero estos no permiten aproximarse a un cálculo real sobre el cumplimiento y avances de estos indicadores de impacto y resultado. Este es el reto, en suma, que le espera a la institucionalidad en el país: adecuar sus plataformas técnicas y orientación institucional a la reparación de las víctimas y a construir un escenario que no permita la reincidencia de causas y consecuencias que, para el caso de Antioquia (y entre otras afectaciones) han arrojado un total de más de 600 mil personas desplazadas. 


\section{Referencias:}

Acnur. (11 de Febrero de 1998). Principios rectores de los desplazamientos internos. Obtenido de acnur: http:/ /www.acnur.org/biblioteca/pdf/0022.pdf.

Balbin, J., \& Insuasty Rodriguez, A. (2009). Victimas, Violencia y Despojo. Medellín: Litoimpacto.

Balbin , J., \& Insuasty Rodriguez, A. (2010). Las Victimas en Contextos de Violencia e Impunidad: Caso Medellín. Medellín: Instituto Popular de Capacticación.

Corte Constitucional. (22 de Enero de 2004). Sentencia t-025 de 2004. Obtenido de acnur: http:/ /www.acnur.org/t3/fileadmin/scripts/doc.php?file=biblioteca/pdf/2501.

Corte constitucional. (2007). Sentencia T-821. Obtenido de corteconstitucional: http://www.observatorioddr.unal.edu.co/ambitojuridico/catalogo_juridicojyp/sent encia_t-821-07.pdf.

Corte Constitucional. (27 de Mayo de 2009). Norma que autoriza al gobierno para reglamentar la condicion de desplazado. Obtenido de corteconstitucional: http://www.corteconstitucional.gov.co/RELATORIA/2009/C-372-09.htm\#_ftn24.

Corte Constitucional. (15 de Febrero de 2010). Sentencia T-099/10. Obtenido de corteconstitucional:

http://www.corte.corteconstitucional.gov.co/relatoria/2010/T-099-10.htm.

ODDIF. (7 de Diciembre de 2011). Informe técnico de seguimiento a indicadores de goce efectivo de derechos de la población víctima de desplazamiento en el departamento de Antioquia. Obtenido de oddifantioquia: http://www.oddifantioquia.org/informe-degoce-efectivo-de-derechos-2010.html.

Tello, C. (2002). Tesis:El Sistema de Alertas Tempranas. Universidad Externado de Colombia. 
${ }^{5}$ Véase: ODDIF (2011) "Informe técnico de seguimiento a indicadores de goce efectivo de derechos de la población víctima de desplazamiento en el departamento de Antioquia". Investigación realizada por el Observatorio del Desplazamiento Interno Forzado, ODDIF, en el marco del Convenio de Cooperación DAPARD - ACNUR - OPCIÓN LEGAL, Número 2011-CF26-015 para la atención de la población desplazada.

${ }^{6}$ En línea: http://www.acnur.org/biblioteca/pdf/0022.pdf. Principios rectores de los desplazamientos internos. Versión en español. 2008.

${ }^{7}$ Para la lectura de los resultados del indicador es necesario considerar el fallo del Consejo de Estado respecto a la 'extemporaneidad como causal de no inclusión en el Registro Único de Población Desplazada (RUPD)' mediante sentencia del 12 de junio de 2008, expediente 2002 036; este factor explica el mayor número personas valoradas e incluidas de acuerdo con los registros de los años 2009 y 2010, sin que necesariamente estas cifras estén asociadas a 'factores de riesgo del desplazamiento forzado'.

8 En linea: http://www.corteconstitucional.gov.co/RELATORIA/2009/C-37209.htm\#_ftn24. Sentencia C-372/09 "Norma que autoriza al gobierno para reglamentar la condición de desplazado".

9 En Línea: http://www.corte.corteconstitucional.gov.co/relatoria/2010/T-099-10.htm. Sentencia T-099/10.

${ }^{10}$ Los aspectos técnicos de la medición (Fichas Técnicas) pueden ser consultados en el "Informe técnico de seguimiento a indicadores de goce efectivo de derechos de la población víctima de desplazamiento en el departamento de Antioquia" (ODDIF 2011). 